\title{
An accurate description of the ground and excited states of $\mathrm{CH}$
}

\author{
Apostolos Kalemos and Aristides Mavridis \\ Department of Chemistry, Laboratory of Physical Chemistry, National and Kapodistrian University \\ of Athens, P.O. Box 64004, 15710 Zografou, Athens, Greece
}

\section{Aristophanes Metropoulos}

Institute of Theoretical and Physical Chemistry, National Hellenic Research Foundation, 48 Vassileos Constantinou Avenue, Athens, 11635 Greece

(Received 18 June 1999; accepted 9 September 1999)

\begin{abstract}
With the high accuracy afforded by the sextuple correlation consistent basis set of Dunning, we have calculated energy levels, dissociation energies, equilibrium distances, and other spectroscopic constants for eleven valence and four Rydberg states of the $\mathrm{CH}$ radical. Comparisons with experimental and previous theoretical results are made for each state that has been treated. An understanding of their binding is attempted by means of simple valence bond-Lewis diagrams. (C) 1999 American Institute of Physics. [S0021-9606(99)30245-2]
\end{abstract}

\section{INTRODUCTION}

The $\mathrm{CH}$ radical was first detected in the laboratory as early as $1918,{ }^{1,2}$ and has been the subject of numerous spectroscopic investigations in the optical, infrared, far infrared, and microwave regions seeking to establish various spectroscopic constants, binding energies, equilibrium distances, dipole moments, lifetimes of excited states (lately rotationally resolved), hyperfine parameters, photodissociation and photoionization processes, as well as dissociative recombination mechanisms. ${ }^{3-92}$ Its presence (along with other hydrides) in extraterrestrial regions ${ }^{93-117}$ and in flames ${ }^{118-139}$ has been a strong reason for the lasting interest in this radical, which interest recently has increased due to the presence of $\mathrm{CH}$ in reactions on surfaces of metal catalysts such as $\mathrm{Ru}$ and Pd. ${ }^{140,141}$ In a series of articles, Herzberg and co-workers ${ }^{16,19,26,30}$ have obtained spectra of $\mathrm{CH}$ and $\mathrm{CD}$ by flash photolysis of normal and deuterated diazomethane (as their precursor), and from the analysis of these spectra, they have obtained spectroscopic constants for the ground and excited states of $\mathrm{CH}$ and $\mathrm{CD}$ as high as about $65000 \mathrm{~cm}^{-1}$ $(\sim 8 \mathrm{eV})$. Some of these constants have been refined by other workers, but the data collection in Ref. 30 (almost duplicated in Ref. 48) still seems to be the main source of such constants. Up until 1985 the spectroscopy of states above 50000 $\mathrm{cm}^{-1}$ was not well known except for the data provided by Herzberg's work. ${ }^{30}$ Since then, using the photodissociation of organic precursors of $\mathrm{CH}$, resonant multiphoton ionization spectra with mass and photoelectron analysis have been obtained and have yielded new states and previously unobserved bands, and some inconsistencies of previous assignments have been resolved. ${ }^{56,59,64,66,136}$ Yet, very few constants for these states have been obtained so far from the analysis of these new spectra. The existence of the spectroscopically elusive $a^{4} \Sigma^{-}$state which lies just above the ground state has been detected in the gas phase by laser photoelectron spectrometry of $\mathrm{CH}^{-}$(Refs. 142, 143) and later by laser magnetic resonance. ${ }^{144}$ Along with the spectroscopic constants of $\mathrm{CH}$, similar data for its $\mathrm{CD}$ isotope have also been obtained ${ }^{8,9,11,21,29-32,48,145-147}$ as well as constants for its ${ }^{13} \mathrm{CH}$ isotope ${ }^{148-151}$ and the hyperfine parameters of $X^{2} \Pi .{ }^{149}$ Spectra of $\mathrm{CH}$ in a low temperature matrix have recently been obtained. ${ }^{152,153}$

Theoretically, first-row hydrides were the main targets of early molecular computations beyond $\mathrm{H}_{2}$ and $\mathrm{H}_{2}^{+}$. One reason for this was the relative abundance of early spectroscopic data for these molecules (and their cations) thus furnishing equilibrium separations, spectroscopic constants, and ground state symmetries. Another reason was the fact that only few basis functions were needed for $\mathrm{H}$, thus allowing sufficient functions to be placed on the other nucleus for a satisfactory representation of the orbitals. Also, the correlation energy was slightly easier to estimate, since upon separation $\mathrm{H}$ has no correlation energy; in addition, there is little difference between the inner shells of the hydride and of the corresponding first-row atom. Some of the early treatments were qualitative ${ }^{154-156}$ and some employed Slater-type molecular orbitals for valence electrons without self consistency considerations. ${ }^{157,158}$ However, Hartree-Fock-Roothaan type calculations were employed soon, some with limited CI, and some with further semiempirical correlation corrections and exponent optimization in the expansions of the Slatertype functions. The very first simple calculation of $\mathrm{CH}$ apparently was that of Niira and Oohata ${ }^{157}$ in 1952 while two years later Higuchi ${ }^{159}$ did the first CI calculation. Over the years, the progressively developed sophisticated methods were also applied to the first and second-row hydrides; semiempirical methods estimating spectroscopic constants by combining experimental and theoretical results were also used. The $\mathrm{CH}$ radical has been a part of many of these calculations. ${ }^{160-234}$ A reasonably detailed bibliography of calculations of first-row hydrides up to 1966 was given by Cade and Huo, ${ }^{166}$ while Meyer and Rosmus ${ }^{186}$ give references to such calculations from 1966 to 1975.

The volume of theoretical work naturally deals with much the same topics as the experimental papers. Since we are only sketching previous work on $\mathrm{CH}$ (our references are certainly not exhaustive), we will touch only briefly on pre- 
vious theoretical work most relevant to our present purposes. Liu and Verhaegen ${ }^{170}$ employed $a b$ initio LCAO-MO-SCF calculations with semiempirical correlation corrections and produced limited potential-energy curves (PEC) for seven states and obtained acceptable spectroscopic constants for six of them. The most extensive totally $a b$ initio work on $\mathrm{CH}$ was that of Lie et al. ${ }^{175}$ and Hinze et al. ${ }^{188,189}$ who employed a CI method with Slater orbitals as basis functions. They calculated very accurate PECs for the first five states of $\mathrm{CH}$ as well as their properties, spectroscopic constants, transition probabilities, lifetimes, and hyperfine parameters. Meyer and Rosmus $^{186}$ investigated the ground state of $\mathrm{CH}$ and other hydrides by PNO-CI and CEPA methods with Gaussian basis sets with an eye towards investigating the reliability of these methods. Their results, however, are somewhat inferior to those of Lie et al. Sun and Freed ${ }^{196}$ have used quasidegenerate MBPT with Slater orbitals as basis functions and have obtained a large number of $\mathrm{CH}$ potential curves and spectroscopic constants for eight states. However, they have not given absolute energy values; the calculations do not converge beyond 5 bohr and the derived constants of the five lowest states do not compare favorably with experimental data. Van Dishoeck ${ }^{205}$ has investigated the photodissociation processes of $\mathrm{CH}$ by a multireference CI method with Gaussian basis sets (MRDCI) and has generated potential curves for states up to about $9 \mathrm{eV}$ from the ground state. However, the minimum of the $X^{2} \Pi$ ground state is about $16 \mathrm{mH}$ higher than the latest value (vide infra) probably because of the limited size of the basis set and the somewhat large threshold of $10 \mu \mathrm{H}$, which generated about 5000 configuration functions $(\mathrm{CF})$. Notice that with the method used, the computed properties do not correspond to the extrapolated (near full-CI) energies but to the wavefunction corresponding to the $5000 \mathrm{CFs}^{227} \mathrm{Also}$, no equilibrium distances (except for the $X^{2} \Pi$ state) or other spectroscopic constants were given, since this was not the purpose of the work, and the binding (dissociation) energies for some states were small compared to the experimental values (almost half as small for the $B$ state). Grev and Schaefer ${ }^{223}$ using the $\operatorname{CCSD}(\mathrm{T})$ method with four basis sets have calculated the ground state and atomization energies, with and without core correlation, and the heats of formation of $\mathrm{CH}$ and other species. Peterson et al. $^{224}$ and Peterson and Dunning ${ }^{233}$ have done benchmark calculations for $\mathrm{CH}$ and other species (testing various basis sets and methods) and have obtained accurate energies and spectroscopic constants, but only for the ground state of each species. Hettema and Yarkony ${ }^{228}$ employing the full BreitPauli spin-orbit Hamiltonian with MRCI functions have studied the spin-forbidden radiative decay of the $\mathrm{CH}\left(a^{4} \Sigma^{-}\right)$ state and have found its lifetime to be between 12 and $8 \mathrm{~s}$ depending on the vibrational state. They have also generated potential curves for the $X, a, A$, and $C$ states and have computed their dipole moments. Martin, ${ }^{234}$ using the $\operatorname{CCSD}(\mathrm{T})$ method with correlation consistent basis sets, has carried out a very accurate calculation for the ground (only) state of $\mathrm{CH}$ and some other hydrides, and has obtained reliable spectroscopic constants and dissociation energies, but he has not given absolute energy values.

Although the ground state of $\mathrm{CH}$ has been well charac- terized, there is still a lack of accurate data for the excited states, especially the ones above $50000 \mathrm{~cm}^{-1}$. With spectroscopic experiments appearing in the literature involving highly excited states it is obvious that accurate values of constants for these states are needed to corroborate the experimental findings and to help experimentalists to correctly assign new bands and lines.

Thus, the purpose of the present work is to produce accurate PECs and accurate spectroscopic constants, and to investigate the binding modes for as many states as possible. We generate curves for all the states arising from the ${ }^{2} S$ state of $\mathrm{H}$ and the ${ }^{3} P,{ }^{1} D,{ }^{1} S,{ }^{5} S$, the doublet states of ${ }^{3} P,{ }^{1} P$, and one state stemming from the ${ }^{3} D$ of $\mathrm{C}$. We also compute their equilibrium distances, binding energies, and vibrational and rotational interaction constants as well as their dipole moments. For easy reference, Table I shows the quantities of interest in the present work which have been computed by some of the previous authors.

\section{BASIS SETS AND COMPUTATIONAL APPROACH}

The correlation consistent cc-pVnZ basis sets of Dunning and coworkers ${ }^{235}$ have been employed throughout the present work. For the $\mathrm{H}$ atom the $n=4$ basis set was employed in all cases. For the $\mathrm{C}$ atom the $n=6$ (sextuple) basis was selected but with the functions $i$ of $l=6$ angular momentum removed. For the $\mathrm{CH}$ Rydberg states arising from the ${ }^{3} P$ and ${ }^{1} P\left(2 p^{1} 3 s^{1}\right)$ states of $\mathrm{C}$ we have used the corresponding augmented basis set but without the diffuse functions of $h$ symmetry. Thus, our largest basis set expansion reads $(17 s 11 p 6 d 5 f 4 g 2 h / 6 s 3 p 2 d 1 f)$ generally contracted to [8s7p $6 d 5 f 4 g 2 h / 4 s 3 p 2 d 1 f]$ containing 182 Gaussian functions.

Starting with a CASSCF calculation, we have distributed the five valence electrons in ten active orbitals $(2 s+2 p$ $+3 d$ of $\mathrm{C}$ and $1 s$ of $\mathrm{H}$ ) for the valence states, and in eleven active orbitals (adding a $3 s$ diffuse function on C) for the Rydberg states. This generated about 800 and about 1400 $\mathrm{CFs}$, respectively, depending on the molecular symmetry.

All CASSCF vectors were optimized under $C_{2 v}$ symmetry and equivalence restrictions, thus acquiring axial symmetry. Dynamical valence correlation was obtained by single and double excitations out of the CAS (i.e., CASSCF $+1+2=\mathrm{MRCI}$ ) using the internal contraction scheme as implemented in the MOLPRO 96.4 package. ${ }^{236}$ Of course, at the CI level, calculated states conform to the irreducible representations of the $C_{2 v}$ point group, therefore do not possess pure axial symmetry. In particular states of $\Sigma^{+}$, $\Sigma^{-}, \Pi^{ \pm}$and $\Delta^{ \pm}$symmetries are calculated as $A_{1}, A_{2}, B_{1}$, and $A_{1}\left(\right.$ or $\left.A_{2}\right)$, respectively. The uncontracted MRCI space ranges from 1500000 to $4000000 \mathrm{CFs}$ while the internally contracted space ranges from 300000 to $1500000 \mathrm{CFs}$, depending on the molecular symmetry. For a stand alone $\mathrm{C}$ atom, spherical symmetry was implemented by performing state averaged CASSCF calculations before the MRCI ones.

The energy loss for the $\mathrm{CH}\left(X^{2} \Pi\right)$ state due to internal contraction has been estimated by Peterson et al. ${ }^{224}$ to be about $1 \mathrm{mh}$ at the MRCI/cc-pVQZ level. Because of the large size of the basis sets used here, no correction for the basis set superposition error was deemed necessary. Size ex- 
TABLE I. Comparison of the best energies and spectroscopic parameters as calculated by various authors and as determined experimentally. In all CI calculations the $\mathrm{C}(1 s)$ electrons were kept frozen unless indicated otherwise. (Energies up to four decimal places.)

\begin{tabular}{|c|c|c|c|c|c|c|c|c|c|c|}
\hline State & $\begin{array}{l}\text {-Energy } \\
\text { (hartree) }\end{array}$ & $\begin{array}{c}T_{e} \\
(\mathrm{eV})\end{array}$ & $\begin{array}{c}D_{e},\left[D_{0}\right] \\
\quad(\mathrm{eV})\end{array}$ & $\begin{array}{c}r_{e},\left[r_{0}\right] \\
(\AA)\end{array}$ & $\begin{array}{c}\mu \\
\text { (D) }\end{array}$ & $\begin{array}{c}\omega_{e} \\
\left(\mathrm{~cm}^{-1}\right)\end{array}$ & $\begin{array}{c}\omega_{e} \chi_{e} \\
\left(\mathrm{~cm}^{-1}\right)\end{array}$ & $\begin{array}{c}\alpha_{e} \\
\left(\mathrm{~cm}^{-1}\right)\end{array}$ & $\begin{array}{c}\bar{D}_{e}\left(10^{-4}\right) \\
\left(\mathrm{cm}^{-1}\right)\end{array}$ & Reference \\
\hline \multirow[t]{20}{*}{$X^{2} \Pi$} & $\cdots$ & 0.0 & 2.98 & 1.09 & 1.97 & 3100 & & & & $159(1954)^{\mathrm{a}}$ \\
\hline & 38.464 & & 2.97 & & 1.54 & & & & & $160(1958)^{\mathrm{b}}$ \\
\hline & 38.2796 & & 2.47 & 1.104 & & 3053 & 55.5 & 0.4712 & & $166(1967)^{c}$ \\
\hline & 38.2794 & & & $1.124^{\mathrm{d}}$ & 1.57 & & & & & $168(1968)^{d}$ \\
\hline & 38.479 & & 3.46 & 1.106 & & 3108 & & & & $170(1970)^{\mathrm{e}}$ \\
\hline & 38.4104 & & 3.51 & 1.118 & 1.450 & 2886.1 & 82.0 & 0.589 & $14.4^{\mathrm{f}}$ & $175(1973)^{\mathrm{g}}$ \\
\hline & 38.4083 & & 3.47 & 1.122 & 1.43 & 2841.7 & 64.4 & 0.532 & & $186(1975)^{\mathrm{h}}$ \\
\hline & $\cdots$ & 0.0 & & 1.133 & & 2519.1 & 19.17 & 0.737 & & $196(1981)^{\mathrm{i}}$ \\
\hline & 38.3852 & & {$[3.32]$} & 1.124 & & 2828.3 & 62.52 & 0.520 & & $198(1983)^{\mathrm{j}}$ \\
\hline & 38.4069 & 0.0 & 3.45 & 1.1199 & & & & & & $205(1987)^{\mathrm{k}}$ \\
\hline & 38.4195 & & 3.609 & $1.104^{1}$ & & & & & & $223(1992)^{1}$ \\
\hline & 38.4702 & & 3.585 & $1.104^{1}$ & & & & & & $223(1992)^{1}$ \\
\hline & 38.4186 & & 3.59 & 1.1201 & & 2850.2 & 64.0 & 0.5374 & & $224(1993)^{\mathrm{m}}$ \\
\hline & $38.4138^{\mathrm{n}}$ & 0.0 & & 1.1224 & & 2851.9 & 66.6 & & & $228(1994)^{\mathrm{n}}$ \\
\hline & 38.4207 & & 3.613 & 1.1202 & & & & & & $233(1997)^{\circ}$ \\
\hline & 38.4720 & & 3.608 & 1.1184 & & & & & & $233(1997)^{\circ}$ \\
\hline & $\ldots$ & & $3.631^{\mathrm{p}}$ & 1.11958 & & 2857.88 & $63.839^{\mathrm{p}}$ & & & $234(1998)^{\mathrm{p}}$ \\
\hline & $\cdots$ & & & 1.11808 & & 2861.72 & $64.554^{\mathrm{q}}$ & & & $234(1998)^{\mathrm{q}}$ \\
\hline & 38.4217 & & 3.615 & 1.1204 & 1.4057 & 2851.0 & 62.15 & 0.542 & 14.85 & present work \\
\hline & $\cdots$ & 0.0 & 3.640 & $1.119786_{8}$ & $1.46 \pm 0.06$ & 2860.75 & 64.44 & 0.5365 & 14.7 & Exp. 48,86 \\
\hline \multirow[t]{9}{*}{$a^{4} \Sigma^{-}$} & $\ldots$ & 0.09 & & 1.08 & 1.07 & 3500 & & & & $159(1954)^{\mathrm{a}}$ \\
\hline & 38.449 & & & & & & & & & $150(1958)^{\mathrm{b}}$ \\
\hline & 38.2344 & & & $1.1026^{\mathrm{d}}$ & 0.89 & & & & & $168(1968)^{\mathrm{d}}$ \\
\hline & 38.445 & & & 1.093 & & 3359 & & & & $170(1970)^{\mathrm{e}}$ \\
\hline & 38.3865 & & 2.84 & 1.086 & 0.663 & 3145.7 & 71.8 & 0.553 & $14.3^{\mathrm{f}}$ & $175(1973)^{\mathrm{g}}$ \\
\hline & $\ldots$ & 0.481 & & 1.114 & & 2947.3 & 83.35 & 0.467 & & $196(1981)^{\mathrm{i}}$ \\
\hline & $\cdots$ & 0.716 & & 1.0912 & & 3117.3 & 80.6 & & & $228(1994)^{\mathrm{n}}$ \\
\hline & 38.3942 & 0.747 & 2.863 & 1.0892 & 0.6531 & 3090.9 & 102.17 & 0.723 & 15.19 & present work \\
\hline & $\cdots$ & 0.742 & [2.723] & [1.0977] & & & & & & Exp. 143, 144 \\
\hline \multirow[t]{11}{*}{$A^{2} \Delta$} & $\cdots$ & 2.75 & & 1.10 & 1.41 & 3300 & & & & $159(1954)^{\mathrm{a}}$ \\
\hline & 38.364 & & & & & & & & & $150(1958)^{\mathrm{b}}$ \\
\hline & 38.1803 & & & $1.1026^{\mathrm{d}}$ & 0.91 & & & & & $168(1968)^{d}$ \\
\hline & 38.371 & & & 1.090 & & 3111 & & & & $170(1970)^{\mathrm{e}}$ \\
\hline & 38.3031 & & 1.90 & 1.102 & 0.904 & 2970.3 & 98.5 & 0.697 & $15.2^{\mathrm{f}}$ & $175(1973)^{\mathrm{g}}$ \\
\hline & $\cdots$ & 3.074 & & 1.123 & & 2688.8 & 80.17 & 0.812 & & $196(1981)^{\mathrm{i}}$ \\
\hline & 38.2794 & & {$[1.45]$} & 1.111 & & 2863.6 & 96.15 & 0.696 & & $198(1983)^{j}$ \\
\hline & $\cdots$ & $3.00^{\mathrm{k}}$ & 1.88 & & & & & & & $205(1987)^{\mathrm{k}}$ \\
\hline & $\cdots$ & 2.922 & & 1.1073 & & 2926.9 & 103.8 & & & $228(1994)^{\mathrm{n}}$ \\
\hline & 38.3151 & 2.901 & 1.975 & 1.1056 & 0.8434 & 2911.1 & 91.99 & 0.675 & 15.42 & present work \\
\hline & $\cdots$ & 2.870 & 2.010 & 1.1031 & $0.77 \pm 0.07$ & 2914.10 & 81.40 & 0.6354 & 15.4 & Exp. $30,86,74$ \\
\hline \multirow[t]{8}{*}{$B^{2} \Sigma^{-}$} & $\ldots$ & 3.07 & & 1.13 & 1.89 & 3100 & & & & $159(1954)^{\mathrm{a}}$ \\
\hline & 38.1583 & & & $1.1861^{\mathrm{d}}$ & 1.54 & & & & & $168(1968)^{\mathrm{d}}$ \\
\hline & 38.358 & & & 1.124 & & 2543 & & & & $170(1970)^{\mathrm{e}}$ \\
\hline & 38.2908 & & 0.23 & 1.173 & 1.389 & 2141.7 & 223.2 & 1.933 & $22.6^{\mathrm{f}}$ & $175(1973)^{\mathrm{g}}$ \\
\hline & $\cdots$ & 3.180 & & 1.270 & & 2081.1 & 385.7 & 1.579 & & $196(1981)^{\mathrm{i}}$ \\
\hline & $\cdots$ & $3.24^{\mathrm{k}}$ & 0.29 & & & & & & & $205(1987)^{\mathrm{k}}$ \\
\hline & 38.3026 & 3.241 & 0.372 & 1.1768 & 1.3285 & 2167.1 & 173.72 & 1.11 & 19.38 & present work \\
\hline & $\cdots$ & 3.231 & 0.409 & 1.1640 & & 2246.42 & 225.7 & 1.4823 & 16.3 & Exp. 30, 89 \\
\hline \multirow[t]{9}{*}{$C^{2} \Sigma^{+}$} & $\ldots$ & 3.65 & & 1.11 & 1.41 & 3200 & & & & $159(1954)^{\mathrm{a}}$ \\
\hline & 38.1283 & & & $1.1132^{\mathrm{d}}$ & 0.94 & & & & & $168(1968)^{\mathrm{d}}$ \\
\hline & 38.333 & & & 1.097 & & 3085 & & & & $170(1970)^{\mathrm{e}}$ \\
\hline & 38.2627 & & 0.78 & 1.111 & 0.955 & 2887.5 & 106.8 & 0.771 & $15.5^{\mathrm{f}}$ & $175(1973)^{\mathrm{g}}$ \\
\hline & $\cdots$ & 4.095 & & 1.129 & & 2558.9 & 88.83 & 0.794 & & $196(1981)^{\mathrm{i}}$ \\
\hline & $\cdots$ & $4.02^{\mathrm{k}}$ & 0.86 & & & & & & & $205(1987)^{\mathrm{k}}$ \\
\hline & $\cdots$ & 3.9904 & & 1.1179 & & 2853.3 & 133.0 & & & $228(1994)^{\mathrm{n}}$ \\
\hline & 38.2758 & 3.983 & 0.910 & 1.1164 & 0.9055 & 2837.3 & 87.76 & 0.429 & 14.91 & present work \\
\hline & $\ldots$ & 3.943 & 0.940 & 1.1143 & & 2840.2 & 125.96 & 0.7185 & $15.55^{\mathrm{f}}$ & Exp. 30,48 \\
\hline
\end{tabular}


TABLE I. (Continued.)

\begin{tabular}{|c|c|c|c|c|c|c|c|c|c|c|}
\hline State & $\begin{array}{c}\text {-Energy } \\
\text { (hartree) }\end{array}$ & $\begin{array}{c}T_{e} \\
(\mathrm{eV})\end{array}$ & $\begin{array}{c}D_{e},\left[D_{0}\right] \\
\quad(\mathrm{eV})\end{array}$ & $\begin{array}{c}r_{e},\left[r_{0}\right] \\
(\AA)\end{array}$ & $\begin{array}{c}\mu \\
\text { (D) }\end{array}$ & $\begin{array}{c}\omega_{e} \\
\left(\mathrm{~cm}^{-1}\right)\end{array}$ & $\begin{array}{c}\omega_{e} \chi_{e} \\
\left(\mathrm{~cm}^{-1}\right)\end{array}$ & $\begin{array}{c}\alpha_{e} \\
\left(\mathrm{~cm}^{-1}\right)\end{array}$ & $\begin{array}{c}\bar{D}_{e}\left(10^{-4}\right) \\
\left(\mathrm{cm}^{-1}\right)\end{array}$ & Reference \\
\hline \multirow[t]{5}{*}{$E^{2} \Pi$} & $\ldots$ & 7.09 & & 1.14 & 1.19 & 3100 & & & & $\overline{159(1954)^{\mathrm{a}}}$ \\
\hline & 38.210 & & & 1.167 & & 2643 & & & & $170(1970)^{\mathrm{e}}$ \\
\hline & $\cdots$ & 7.558 & & 1.137 & & 3284.9 & 905.2 & 0.261 & & $196(1981)^{\mathrm{i}}$ \\
\hline & $\ldots$ & $7.43^{\mathrm{k}}$ & & & & & & & & $205(1987)^{\mathrm{k}}$ \\
\hline & $\begin{array}{c}38.1513 \\
\ldots\end{array}$ & $\begin{array}{l}7.358 \\
(7.488)^{\mathrm{r}}\end{array}$ & & $\begin{array}{l}1.1437 \\
(1.15)\end{array}$ & 0.8334 & 2743.0 & 57.63 & 0.512 & 14.24 & $\begin{array}{l}\text { present work } \\
\text { Exp. } 48\end{array}$ \\
\hline
\end{tabular}

${ }^{a}$ Minimal STF basis set with small CI; dipole moments from SCF calculations.

${ }^{\mathrm{b}}$ Minimal STF basis set with small CI plus semiempirical correlation corrections; all at $2.124 \mathrm{bohr}$.

${ }^{c} \mathrm{SCF}$ with optimized STF exponents; Basis set: C ( $\left.5 s 4 p 2 d 1 f\right)$; H ( $\left.3 s 1 p\right)$; potential curve (1.6 to 3.5 bohr).

${ }^{\mathrm{d}}$ Same as (c) but without potential curve; all at the indicated experimental $r$ 's ( $A^{2} \Delta$ state's $r$ used in $a^{4} \Sigma^{-}$state).

${ }^{e} \mathrm{LCAO}-\mathrm{MO}-\mathrm{SCF}$ with a semiempirical correlation estimate; basis set as in (c).

${ }^{\mathrm{f}}$ This quantity corresponds to $D_{\mathrm{v}=0}\left(10^{-4}\right) \mathrm{cm}^{-1}$.

${ }^{g}$ Medium size CI with NO's and an optimized STF basis set (C/H: $\left.6 s 4 p 2 d 2 f 4 s 3 p 2 d\right)$; potential curves.

${ }^{\mathrm{h}} \mathrm{CEPA}$ with the GTO basis set: C: $4 s 4 p 2 d 1 f$; H: $4 s 2 p 1 d$.

${ }^{\mathrm{i}} \mathrm{Quasidegenerate}$ MBPT with the STF basis set $(\mathrm{C} / \mathrm{H}):(4 s 3 p 1 d / 2 s 1 p)$.

${ }^{\mathrm{j}}$ Large CASSCF with the basis set: C: $6 s 6 p 3 d$; H: $4 s 3 p$; active space: $5 \sigma 3 \pi$ and $1 \delta$ (propert.) or $2 \delta$ (energies).

${ }^{\mathrm{k}}$ MRDCI $\left(10 \mu \mathrm{H}\right.$ threshold) with customized basis sets. $T_{e}$ 's are vertical excitations from $r_{e}$ of the ground state.

${ }^{\mathrm{l}} \mathrm{CCSD}(\mathrm{T})$ with customized basis set; $r_{e}$ is the equilibrium distance at the SCF level; 1st line: frozen core; 2nd line: all electrons correlated.

${ }^{\mathrm{m}} \mathrm{CASSCF}+1+2$ with the correlation consistent basis set cc-pV5Z.

${ }^{\mathrm{n}} \mathrm{SA}$-CASSCF/CI with the cc-pVTZ basis set; the energy value corresponds to $r=2.116 \mathrm{bohr}$.

${ }^{\circ} \mathrm{CCSD}(\mathrm{T})$ with the basis sets $(\mathrm{C} / \mathrm{H})$ : cc-pV $(5 \mathrm{Z} / \mathrm{QZ})$, 1st line: frozen core, and cc-pCV(QZ/QZ), 2nd line all electrons correlated.

${ }^{\mathrm{p}} \mathrm{CCSD}(\mathrm{T})$ with the cc-pV6Z basis set. Extrapolated to infinite-basis limit gives $D_{e}=3.643 \mathrm{eV}$ and $D_{0}=3.468 \mathrm{eV} ; \omega_{e} y_{e}=0.305, \omega_{e} z_{e}=-0.004 \mathrm{~cm}^{-1}$.

${ }^{q} \operatorname{CCSD}(\mathrm{T})$ "best estimate" with cc-pVnZ basis sets including core correlation; $\omega_{e} y_{e}=0.300, \omega_{e} z_{e}=-0.005 \mathrm{~cm}^{-1}$.

${ }^{\mathrm{r}}$ The $T_{0}$ value is $7.313 \mathrm{eV}$; the $T_{e}$ estimate is uncertain.

tensivity errors are also small; at the MRCI level our largest such error is about $0.4 \mathrm{mh}$ for the $H^{2} \Pi$ Rydberg state and $0.08 \mathrm{mh}$ for the valence states, as obtained by subtracting the CI fragments from the MRCI supermolecule.

Excited states of ${ }^{2} \Pi$ and ${ }^{2} \Sigma^{+}$symmetry have been obtained via the state average (SA) methodology employing $w(1,1,1,1)$ weighting vectors. Energy losses due to the SA approach are not significant; for instance, for the states $X^{2} \Pi$ and $C^{2} \Sigma^{+}$equilibrium energy differences with and without the SA amount to 0.2 and $1 \mathrm{mh}$, respectively.

Spectroscopic constants for the four isotopic species ${ }^{12} \mathrm{CH},{ }^{12} \mathrm{CD},{ }^{13} \mathrm{CH}$, and ${ }^{13} \mathrm{CD}$ were extracted by fitting 20 to 30 equidistant energy points $(0.02$ bohr apart $)$ around the equilibrium geometry, and then applying a standard Dunham analysis. $^{237}$

\section{RESULTS AND DISCUSSION}

To estimate the sufficiency of our basis set, we computed the energy levels of the $\mathrm{C}$ atom in a spherically averaged manner as previously indicated. It was found that the SCF energy of the ${ }^{3} P$ ground state was $-37.688612 \mathrm{~h}$, just $7 \mu \mathrm{h}$ above the numerical result. ${ }^{238}$ Table II lists the absolute MRCI energies and energy gaps $(\Delta E)$ of the ${ }^{3} P\left(2 s^{2} 2 p^{2}\right)$, ${ }^{1} D\left(2 s^{2} 2 p^{2}\right),{ }^{1} S\left(2 s^{2} 2 p^{2}\right),{ }^{5} S\left(2 s^{1} 2 p^{3}\right),{ }^{3} P\left(2 s^{2} 2 p^{1} 3 s^{1}\right)$, ${ }^{1} P\left(2 s^{2} 2 p^{1} 3 s^{1}\right)$, and ${ }^{3} D\left(2 s^{1} 2 p^{3}\right)$ terms calculated as indicated in the previous section. Nearly all energy gaps are in excellent agreement with the experiment, showing that the chosen basis set and correlation treatment are adequate for all the computed $\mathrm{CH}$ states. The two small deviations from this agreement are the ${ }^{1} P\left(2 s^{2} 2 p^{1} 3 s^{1}\right) \leftarrow{ }^{3} P\left(2 s^{2} 2 p^{2}\right)$ and ${ }^{3} D\left(2 s^{1} 2 p^{3}\right) \leftarrow{ }^{3} P\left(2 s^{2} 2 p^{2}\right)$ energy splittings, which are overestimated by 0.060 and $0.148 \mathrm{eV}$, respectively.
Table III displays total energies $(E)$, binding energies $\left(D_{e}\right)$, equilibrium bond lengths $\left(r_{e}\right)$, dipole moments $(\mu)$, and energy gaps $\left(T_{e}\right)$ of all the calculated, bond $\mathrm{CH}$ states. Two more states have been calculated, the $b^{4} \Pi$ and $d^{6} \Sigma^{-}$, but they are repulsive and thus not listed in this table. Tables IV-VII list spectroscopic constants for four isotopic species $\left({ }^{12} \mathrm{C}-\mathrm{H},{ }^{12} \mathrm{C}-\mathrm{D},{ }^{13} \mathrm{C}-\mathrm{H},{ }^{13} \mathrm{C}-\mathrm{D}\right)$. PECs for all computed states are shown in Fig. 1.

In what follows we discuss the important characteristics of every state. An effort is made to analyze the chemical binding, using simple valence bond-Lewis (vbL) pictures.

\section{A. The ground $X^{2} \Pi$ state}

We can envisage the formation of the $X^{2} \Pi$ state as the result of $\mathrm{C}\left({ }^{3} P ; M= \pm 1\right)+\mathrm{H}\left({ }^{2} S\right)$ reaction. The bonding can be represented by the following vbL diagram:

TABLE II. Total energies $E$ (hartree) of the ${ }^{3} P,{ }^{1} D,{ }^{1} S,{ }^{5} S,{ }^{3} P,{ }^{1} P$, and ${ }^{3} D$ carbon states and corresponding energy splittings $\Delta E(\mathrm{eV})$ with respect to the ground ${ }^{3} P$ state at the MRCI level of theory. Experimental values in parentheses.

\begin{tabular}{ccc}
\hline \hline State & $-E$ & $\Delta E^{\mathrm{a}}$ \\
\hline${ }^{3} P\left(2 s^{2} 2 p^{2}\right)$ & 37.788854 & $0.0(0.0)$ \\
${ }^{1} D\left(2 s^{2} 2 p^{2}\right)$ & 37.742195 & $1.270(1.260)$ \\
${ }^{1} S\left(2 s^{2} 2 p^{2}\right)$ & 37.689894 & $2.693(2.680)$ \\
${ }^{5} S\left(2 s 2 p^{3}\right)$ & 37.635375 & $4.176(4.179)$ \\
${ }^{3} P\left(2 s^{2} 2 p^{1} 3 s^{1}\right)$ & 37.512859 & $7.510(7.545)$ \\
${ }^{1} P\left(2 s^{2} 2 p^{1} 3 s^{1}\right)$ & 37.504361 & $7.741(7.681)$ \\
${ }^{3} D\left(2 s 2 p^{3}\right)$ & 37.491569 & $8.090(7.942)$ \\
\hline \hline
\end{tabular}

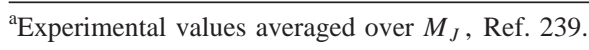


TABLE III. Total energies $E$ (hartree), dissociation energies $D_{e}(\mathrm{kcal} / \mathrm{mol})$, bond distances $r_{e}(\AA)$, dipole moments $\mu(\mathrm{D})$, and energy gaps $T_{e}(\mathrm{kcal} / \mathrm{mol})$ of the calculated states of the $\mathrm{C}-\mathrm{H}$ system.

\begin{tabular}{|c|c|c|c|c|c|c|}
\hline State & Method $^{a}$ & $-E$ & $D_{e}{ }^{\mathrm{b}}$ & $r_{e}$ & $\mu$ & $T_{e}$ \\
\hline \multirow[t]{4}{*}{$X^{2} \Pi$} & CASSCF & 38.365769 & 71.51 & 1.1291 & 1.3835 & \\
\hline & MRCI & 38.421680 & 83.37 & 1.1204 & 1.4057 & 0.0 \\
\hline & $\mathrm{MRCI}+\mathrm{Q}$ & 38.4228 & 83.68 & 1.1204 & & \\
\hline & Exp. $^{c}$ & & 83.94 & 1.119786 & $1.46 \pm 0.06$ & 0.0 \\
\hline \multirow[t]{4}{*}{$a^{4} \Sigma^{-}$} & CASSCF & 38.348569 & 59.03 & 1.0834 & 0.6292 & \\
\hline & MRCI & 38.394231 & 66.03 & 1.0892 & 0.6531 & 17.22 \\
\hline & $\mathrm{MRCI}+\mathrm{Q}$ & 38.3950 & 66.23 & 1.0898 & & \\
\hline & Exp. $^{\mathrm{d}}$ & & $62.80 \pm 0.23$ & 1.0977 & $\ldots$ & $17.11 \pm 0.18$ \\
\hline \multirow[t]{4}{*}{$A^{2} \Delta$} & CASSCF & 38.252503 & 31.15 & 1.1236 & 0.7634 & \\
\hline & MRCI & 38.315088 & 45.54 & 1.1056 & 0.8434 & 66.89 \\
\hline & $\mathrm{MRCI}+\mathrm{Q}$ & 38.3165 & 46.05 & 1.1052 & & \\
\hline & Exp. $^{\mathrm{e}}$ & & 46.35 & 1.1031 & $0.77 \pm 0.07$ & 66.19 \\
\hline \multirow[t]{4}{*}{$B^{2} \Sigma^{-}$} & CASSCF & 38.251060 & -2.84 & 1.2353 & 1.3854 & \\
\hline & MRCI & 38.302579 & 8.59 & 1.1468 & 1.3285 & 74.74 \\
\hline & $\mathrm{MRCI}+\mathrm{Q}$ & 38.3036 & 8.94 & 1.1748 & & \\
\hline & Exp. ${ }^{f}$ & & 9.43 & 1.1640 & $\ldots$ & 74.51 \\
\hline \multirow[t]{4}{*}{$C^{2} \Sigma^{+}$} & CASSCF & 38.207095 & 1.22 & 1.1300 & 0.7762 & \\
\hline & MRCI & 38.275824 & 20.98 & 1.1164 & 0.9055 & 91.85 \\
\hline & $\mathrm{MRCI}+\mathrm{Q}$ & 38.2778 & 21.80 & 1.1134 & & \\
\hline & Exp. ${ }^{g}$ & & 21.68 & 1.1143 & $\cdots$ & 90.93 \\
\hline \multirow[t]{4}{*}{$D^{2} \Sigma^{+}$} & CASSCF & & & & & \\
\hline & MRCI & 38.204769 & 9.35 & 1.6635 & 1.4203 & 136.11 \\
\hline & $\mathrm{MRCI}+\mathrm{Q}$ & 38.2087 & 9.26 & 1.6547 & & \\
\hline & Exp. & & $\ldots$ & $\ldots$ & $\ldots$ & $\ldots$ \\
\hline \multirow[t]{4}{*}{$c^{4} \Sigma^{-}$} & CASSCF & 38.134148 & 12.79 & 1.8586 & 0.1479 & \\
\hline & MRCI & 38.170874 & 22.31 & 1.7866 & 0.2630 & 157.38 \\
\hline & $\mathrm{MRCI}+\mathrm{Q}$ & 38.1715 & 22.60 & 1.7839 & & \\
\hline & Exp. & & $\cdots$ & $\cdots$ & $\cdots$ & $\cdots$ \\
\hline \multirow[t]{4}{*}{$E^{2} \Pi$} & CASSCF & 38.087085 & & 1.1663 & 0.5834 & \\
\hline & MRCI & 38.151279 & & 1.1437 & 0.8334 & 169.68 \\
\hline & $\mathrm{MRCI}+\mathrm{Q}$ & 38.1532 & & 1.1426 & & \\
\hline & Exp. $^{\mathrm{h}}$ & & & 1.15 & $\ldots$ & 172.68 \\
\hline \multirow[t]{4}{*}{$F^{2} \Pi$} & CASSCF & 38.071897 & 58.08 & 1.1696 & 4.0236 & \\
\hline & MRCI & 38.132337 & 75.22 & 1.3751 & 4.4172 & 181.57 \\
\hline & $\mathrm{MRCI}+\mathrm{Q}$ & 38.1346 & 75.76 & 1.3751 & & \\
\hline & Exp. ${ }^{\text {h }}$ & & $\cdots$ & 1.20 & $\ldots$ & 187.62 \\
\hline \multirow[t]{9}{*}{$G^{2} \Sigma^{+}$} & CASSCF & & & & & \\
\hline & MRCI & 38.123104 & 69.30 & 1.1482 & 6.1699 & 187.36 \\
\hline & $\mathrm{MRCI}+\mathrm{Q}$ & 38.1251 & 69.94 & 1.1508 & & \\
\hline & Exp. $^{\mathrm{h}}$ & & $\cdots$ & 1.221 & $\cdots$ & 188.55 \\
\hline & & & (local minimum) & & & \\
\hline & CASSCF & & & & & \\
\hline & MRCI & 38.064757 & 32.68 & 2.6323 & 8.7422 & 223.97 \\
\hline & $\mathrm{MRCI}+\mathrm{Q}$ & 38.0711 & 36.02 & 2.6642 & & \\
\hline & Exp. & & $\cdots$ & $\cdots$ & $\cdots$ & $\cdots$ \\
\hline \multirow[t]{4}{*}{$H^{2} \Pi$} & CASSCF & 38.040009 & 43.75 & 1.4185 & 2.1774 & \\
\hline & MRCI & 38.101144 & 61.03 & 1.3762 & 2.0212 & 201.14 \\
\hline & $\mathrm{MRCI}+\mathrm{Q}$ & 38.1052 & 62.41 & 1.3651 & & \\
\hline & Exp. & & $\cdots$ & $\ldots$ & $\cdots$ & $\cdots$ \\
\hline \multirow[t]{4}{*}{$I^{2} \Sigma^{+}$} & CASSCF & & & & & \\
\hline & MRCI & 38.096382 & 57.85 & 1.2639 & 0.1610 & 204.15 \\
\hline & $\mathrm{MRCI}+\mathrm{Q}$ & 38.0994 & 59.12 & 1.2591 & & \\
\hline & Exp. & & $\cdots$ & $\cdots$ & $\cdots$ & $\cdots$ \\
\hline \multirow[t]{4}{*}{$J^{2} \Delta$} & CASSCF & & & & & \\
\hline & MRCI & 38.069471 & 48.92 & 1.6661 & 0.3515 & 221.05 \\
\hline & $\mathrm{MRCI}+\mathrm{Q}$ & 38.0732 & 46.18 & 1.6612 & & \\
\hline & Exp. & & $\cdots$ & $\cdots$ & $\cdots$ & $\cdots$ \\
\hline
\end{tabular}

${ }^{\mathrm{a}} \mathrm{MRCI}+\mathrm{Q}$ refers to the multireference Davidson correction.

${ }^{\mathrm{b}}$ All $D_{e}$ values are with respect to adiabatic products.

${ }^{\mathrm{c}}$ The $D_{e}, R_{e}, \mu$ values are from Refs. 48,86 , and 25 , respectively.

${ }^{\mathrm{d}}$ The data reported, Ref. 143, correspond to $D_{0}, r_{0}$, and $T_{0}$ values; see text.

${ }^{\mathrm{e}}$ The $r_{e}, T_{e}$ values are from Ref. 86, and $\mu$ is from Ref. 74 .

${ }^{\mathrm{f}}$ References 89 and 240 . For the experimental $D_{e}$ see text.

${ }^{\mathrm{g}} D_{e}$ from Ref. 30, the rest of experimental findings from Ref. 48.

${ }^{\mathrm{h}}$ Reference 48 . 
TABLE IV. Harmonic frequencies $\omega_{e}$, anharmonicities $\omega_{e} \chi_{e}$, rotational vibrational couplings $\alpha_{e}$, and centrifugal distortions $\overline{\boldsymbol{D}}_{\boldsymbol{e}}$ in $\mathrm{cm}^{-1}$ of the ${ }^{12} \mathrm{C}-\mathrm{H}$ system in different states at the MRCI level. Experimental values in parentheses.

\begin{tabular}{ccccc}
\hline \hline State & $\omega_{e}$ & $\omega_{e} \chi_{e}$ & $\alpha_{e}$ & $\bar{D}_{e}\left(10^{-4}\right)$ \\
\hline$X^{2} \Pi$ & 2851.0 & 62.15 & 0.542 & 14.85 \\
& $(2860.75)^{\mathrm{a}}$ & $(64.44)$ & $(0.5365)$ & $(14.7)$ \\
$a^{4} \Sigma^{-}$ & 3090.9 & 102.17 & 0.723 & 15.19 \\
& $\ldots$ & $\ldots$ & $\ldots$ & $\ldots$ \\
$A^{2} \Delta$ & 2911.1 & 91.99 & 0.675 & 15.42 \\
& $(2914.10)^{\mathrm{a}}$ & $(81.40)$ & $(0.6354)$ & $(15.4)$ \\
$B^{2} \Sigma^{-}$ & 2167.1 & 173.72 & 1.11 & 19.38 \\
& $(2246.42)^{\mathrm{b}}$ & $(225.7)^{\mathrm{c}}$ & $(1.4823)$ & $(16.3)$ \\
$C^{2} \Sigma^{+}$ & 2837.3 & 87.76 & 0.429 & 14.91 \\
& $(2840.2)^{\mathrm{d}}$ & $(125.96)$ & $(0.7185)$ & $(15.55)$ \\
$D^{2} \Sigma^{+}$ & 1542.8 & 164.54 & 0.327 & 4.57 \\
& $\ldots$ & $\ldots$ & $\ldots$ & $\ldots$ \\
$c^{4} \Sigma^{-}$ & 1390.3 & 36.66 & 0.059 & 3.80 \\
& $\ldots$ & $\ldots$ & $\ldots$ & $\ldots$ \\
$E^{2} \Pi$ & 2743.0 & 57.63 & 0.512 & 14.24 \\
& $\ldots$ & $\ldots$ & $\ldots$ & $\ldots$ \\
$G^{2} \Sigma^{+\mathrm{e}}$ & 2475.1 & 147.27 & 0.946 & 16.80 \\
& 808.2 & 18.52 & 0.060 & 1.10 \\
$I^{2} \Sigma^{+}$ & 2892.2 & 106.07 & 0.043 & 7.05 \\
& $\ldots$ & $\ldots$ & $\ldots$ & $\ldots$ \\
$J^{2} \Delta$ & 1743.6 & 41.63 & -0.076 & 3.69 \\
& $\ldots$ & $\ldots$ & $\ldots$ & $\ldots$ \\
\hline \hline
\end{tabular}

${ }^{\mathrm{a}}$ Reference 86.

${ }^{\mathrm{b}}$ Reference 89.

${ }^{\mathrm{c}}$ Reference 21.

${ }^{\mathrm{d}}$ Reference 48.

${ }^{\mathrm{e}}$ The first entry corresponds to the global minimum, the second to the local minimum; see text and Fig. 1.

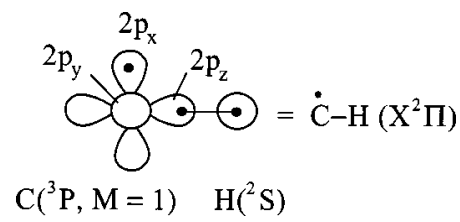

The CASSCF equilibrium Mulliken populations are $(\mathrm{C} / \mathrm{H})$

$$
2 s^{1.81} 2 p_{z}^{1.27} 2 p_{x}^{0.98} 2 p_{y}^{0.06} 3 d^{0.06} / 1 s^{0.79} 2 p_{z}^{0.01} 2 p_{y}^{0.02},
$$

supporting the picture above. At infinity, the corresponding $\mathrm{C}$ atomic distributions are

$$
2 s^{1.93} 2 p_{z}^{1.0} 2 p_{x}^{1.0} 2 p_{y}^{0.05} 3 d^{0.03},
$$

indicating a near degeneracy or GVB $2 s-2 p_{y}$ correlation. In total $0.2 e^{-}$are transferred from $\mathrm{H}$ to $\mathrm{C}$. Therefore, upon completion of the $\mathrm{C}+\mathrm{H}$ interaction, $\sim\left[0.12\left(2 s_{\mathrm{C}}\right)\right.$ $\left.+0.18\left(1 s_{\mathrm{H}}\right)\right]$ electrons are promoted to the $2 p_{z}$ orbital of $\mathrm{C}$.

As it can be seen from Tables I and III, our total MRCI energy of -38.421680 hartree is the lowest valence correlated energy reported so far in the literature. We also report a $D_{e}=83.37 \mathrm{kcal} / \mathrm{mol}$ at the MRCI level which becomes 83.68 $\mathrm{kcal} / \mathrm{mol}$ when the multireference Davidson correction for unlinked clusters is taken into account. Further, if we add to this value a core correlation correction of about $0.13 \mathrm{kcal} /$ mol (vide infra), we obtain a final $D_{e}=83.81 \mathrm{kcal} / \mathrm{mol}, 0.13$ $\mathrm{kcal} / \mathrm{mol}$ lower than the experimental value. Our value of $r_{e}$ is $1.1204 \AA$; assuming a $0.002 \AA$ decrease due to core correlation effects ${ }^{233,234}$ our final $r_{e}$ value is $1.1184 \AA$. Also, our
TABLE V. Harmonic frequencies $\omega_{e}$, anharmonicities $\omega_{e} \chi_{e}$, rotational vibrational couplings $\alpha_{e}$, and centrifugal distortions $\overline{\boldsymbol{D}}_{\boldsymbol{e}}$ in $\mathrm{cm}^{-1}$ of the ${ }^{12} \mathrm{C}-\mathrm{D}$ system in different states at the MRCI level. Experimental values in

\begin{tabular}{|c|c|c|c|c|}
\hline State & $\omega_{e}$ & $\omega_{e} \chi_{e}$ & $\alpha_{e}$ & $\overline{\boldsymbol{D}}_{\boldsymbol{e}}\left(10^{-4}\right)$ \\
\hline$X^{2} \Pi$ & $\begin{array}{l}2093.3 \\
(2100.35)^{b}\end{array}$ & $\begin{array}{c}33.64 \\
(34.16)\end{array}$ & $\begin{array}{c}0.213 \\
(0.212)\end{array}$ & $\begin{array}{c}4.31 \\
(4.32)\end{array}$ \\
\hline$a^{4} \Sigma^{-}$ & $\begin{array}{c}2269.4 \\
\ldots\end{array}$ & $\begin{array}{l}44.09 \\
\ldots\end{array}$ & $\begin{array}{l}0.272 \\
\ldots\end{array}$ & $\begin{array}{l}4.38 \\
\ldots\end{array}$ \\
\hline$A^{2} \Delta$ & $\begin{array}{c}2137.4 \\
(2203.3)\end{array}$ & $\begin{array}{c}49.39 \\
(78.50)\end{array}$ & $\begin{array}{c}0.266 \\
(0.260)\end{array}$ & $\begin{array}{c}4.48 \\
(4.5)\end{array}$ \\
\hline$B^{2} \Sigma^{-}$ & $\begin{array}{c}1591.1 \\
(1652.5)\end{array}$ & $\begin{array}{r}94.14 \\
(123.8)\end{array}$ & $\begin{array}{c}0.437 \\
(0.341)\end{array}$ & $\begin{array}{c}5.62 \\
(6.36)\end{array}$ \\
\hline$C^{2} \Sigma^{+}$ & $\begin{array}{c}2083.2 \\
(2081.3)\end{array}$ & $\begin{array}{c}50.43 \\
(66.79)\end{array}$ & $\begin{array}{c}0.174 \\
(0.283)\end{array}$ & $\begin{array}{l}4.36 \\
(4.5)\end{array}$ \\
\hline$D^{2} \Sigma^{+}$ & $\begin{array}{c}1132.8 \\
\ldots\end{array}$ & $\begin{array}{l}95.93 \\
\ldots\end{array}$ & $\begin{array}{l}0.136 \\
\ldots\end{array}$ & $\begin{array}{c}1.31 \\
\ldots\end{array}$ \\
\hline$c^{4} \Sigma^{-}$ & $\begin{array}{c}1020.8 \\
\ldots\end{array}$ & $\begin{array}{l}19.81 \\
\ldots\end{array}$ & $\begin{array}{l}0.023 \\
\ldots\end{array}$ & $\begin{array}{c}1.10 \\
\ldots\end{array}$ \\
\hline$E^{2} \Pi$ & $\begin{array}{l}2014.0 \\
(2025)\end{array}$ & $\begin{array}{l}30.30 \\
\ldots\end{array}$ & $\begin{array}{l}0.199 \\
\ldots\end{array}$ & $\begin{array}{c}4.13 \\
(4.0)\end{array}$ \\
\hline$G^{2} \Sigma^{+\mathrm{c}}$ & $\begin{array}{r}1817.3 \\
593.4\end{array}$ & $\begin{array}{r}78.35 \\
9.80\end{array}$ & $\begin{array}{l}0.377 \\
0.024\end{array}$ & $\begin{array}{l}4.91 \\
0.319\end{array}$ \\
\hline$I^{2} \Sigma^{+}$ & $\begin{array}{c}2123.5 \\
\ldots\end{array}$ & $\begin{array}{l}57.83 \\
\ldots\end{array}$ & $\begin{array}{l}0.019 \\
\ldots\end{array}$ & $\begin{array}{c}2.04 \\
\ldots\end{array}$ \\
\hline$J^{2} \Delta$ & $\begin{array}{c}1280.2 \\
\ldots\end{array}$ & $\begin{array}{l}22.30 \\
\ldots\end{array}$ & $\begin{array}{c}-0.030 \\
\ldots\end{array}$ & $\begin{array}{c}1.07 \\
\ldots\end{array}$ \\
\hline
\end{tabular}
parentheses. ${ }^{\mathrm{a}}$

${ }^{\text {a Reference }} 48$ (except for $\left.X^{2} \Pi\right)$.

${ }^{\mathrm{b}}$ Reference 147.

${ }^{\mathrm{c}}$ The first entry corresponds to the global minimum, the second to the local, see text and Fig. 1.

dipole moment $\mu=1.406 \mathrm{D}$. Lie et al. ${ }^{175}$ in their remarkable 1973 work on $\mathrm{CH}$ report an energy of -38.41044 hartree, a $D_{e}=80.94 \mathrm{kcal} / \mathrm{mol}$, a $r_{e}=2.113 \mathrm{bohr}=1.1182 \AA$, and a $\mu$ $=1.45 \mathrm{D}$. Peterson and Dunning ${ }^{233}$ give a total (valencecorrelated) energy of -38.420700 hartree, a $D_{e}$ $=83.33 \mathrm{kcal} / \mathrm{mol}$ and a $r_{e}=1.1202 \AA$ at the $\operatorname{CCSD}(\mathrm{T}) / \mathrm{cc}-$ $\mathrm{pV}(5 \mathrm{Z} / \mathrm{QZ})$ level. When they take into account core correlation effects [at the CCSD(T)/cc-pCV(QZ/QZ) level] $D_{e}$ is improved by $0.13 \mathrm{kcal} / \mathrm{mol}$, giving their best value of 83.46 $\mathrm{kcal} / \mathrm{mol}$, and their $r_{e}$ decreases by $0.0018 \AA$. A similar de-

TABLE VI. Harmonic frequencies $\omega_{e}$, anharmonicities $\omega_{e} \chi_{e}$, rotational vibrational couplings $\alpha_{e}$, and centrifugal distortions $\overline{\boldsymbol{D}}_{\boldsymbol{e}}$ in $\mathrm{cm}^{-1}$ of the ${ }^{13} \mathrm{C}-\mathrm{H}$ system in different states at the MRCI level.

\begin{tabular}{crrrr}
\hline \hline State & $\omega_{e}$ & $\omega_{e} \chi_{e}$ & $\alpha_{e}$ & $\overline{\boldsymbol{D}}_{e}\left(10^{-4}\right)$ \\
\hline$X^{2} \Pi$ & 2842.5 & 61.78 & 0.538 & 14.67 \\
$a^{4} \Sigma^{-}$ & 3081.6 & 101.30 & 0.716 & 15.01 \\
$A^{2} \Delta$ & 2902.4 & 91.43 & 0.669 & 15.24 \\
$B^{2} \Sigma^{-}$ & 2160.6 & 172.69 & 1.10 & 19.15 \\
$C^{2} \Sigma^{+}$ & 2828.8 & 87.31 & 0.425 & 14.73 \\
$D^{2} \Sigma^{+}$ & 1568.4 & 152.94 & 0.341 & 4.38 \\
$c^{4} \Sigma^{-}$ & 1386.1 & 36.45 & 0.058 & 3.75 \\
$E^{2} \Pi$ & 2734.8 & 57.27 & 0.507 & 14.07 \\
$G^{2} \Sigma^{+a}$ & 2467.7 & 146.37 & 0.937 & 16.60 \\
& 805.8 & 18.40 & 0.060 & 1.08 \\
$I^{2} \Sigma^{+}$ & 2883.5 & 105.45 & 0.043 & 6.97 \\
$J^{2} \Delta$ & 1738.4 & 41.38 & -0.075 & 3.64 \\
\hline \hline
\end{tabular}

${ }^{a}$ The first entry corresponds to the global minimum, the second to the local; see text and Fig. 1. 
TABLE VII. Harmonic frequencies $\omega_{e}$, anharmonicities $\omega_{e} \chi_{e}$, rotational vibrational couplings $\alpha_{e}$, and centrifugal distortions $\overline{\boldsymbol{D}}_{e}$ in $\mathrm{cm}^{-1}$ of the ${ }^{13} \mathrm{C}-\mathrm{D}$ system in different states at the MRCI level.

\begin{tabular}{ccccc}
\hline \hline State & $\omega_{e}$ & $\omega_{e} \chi_{e}$ & $\alpha_{e}$ & $\overline{\boldsymbol{D}}_{e}\left(10^{-4}\right)$ \\
\hline$X^{2} \Pi$ & 2081.7 & 33.27 & 0.210 & 4.22 \\
$a^{4} \Sigma^{-}$ & 2256.8 & 43.46 & 0.268 & 4.29 \\
$A^{2} \Delta$ & 2125.5 & 48.84 & 0.261 & 4.38 \\
$B^{2} \Sigma^{-}$ & 1582.3 & 93.11 & 0.430 & 5.49 \\
$C^{2} \Sigma^{+}$ & 2071.6 & 49.91 & 0.171 & 4.27 \\
$D^{2} \Sigma^{+}$ & 1126.5 & 94.96 & 0.134 & 1.28 \\
$c^{4} \Sigma^{-}$ & 1015.1 & 19.59 & 0.023 & 1.08 \\
$E^{2} \Pi$ & 2002.8 & 29.95 & 0.196 & 4.04 \\
$G^{2} \Sigma^{+a}$ & 1807.2 & 77.47 & 0.371 & 4.80 \\
$I^{2} \Sigma^{+}$ & 590.1 & 9.69 & 0.024 & 0.312 \\
$J^{2} \Delta$ & 2111.7 & 57.20 & 0.019 & 1.20 \\
\hline \hline
\end{tabular}

${ }^{a}$ The first entry corresponds to the global minimum, the second to the local; see text and Fig. 1.

crease of $0.00192 \AA$ is found by Martin ${ }^{234}$ upon comparing the $\operatorname{CCSD}(\mathrm{T})$ results between the cc-pCV5Z and the aug-ccpV5Z uncontracted levels. The corresponding experimental values are $D_{e}=83.94 \mathrm{kcal} / \mathrm{mol}, r_{e}=1.119786(8) \AA,{ }^{86}$ practically equal to $r_{e}=1.1199 \AA$ given by Huber and Herzberg. ${ }^{48}$ Morino et al.,${ }^{147}$ by estimating $B_{e}$ more accurately, have obtained an experimental $r_{e}=1.118056(29) \AA$, which is in excellent agreement with our core correlation corrected results. Finally, notice that the experimental value of the dipole moment is $1.46 \pm 0.06 \mathrm{D} .^{25}$

\section{B. The $a^{4} \Sigma^{-}$and $c^{4} \Sigma^{-}$states}

Figure 1 shows that the $a^{4} \Sigma^{-}$state traces its origin to the ground state fragments, while the $c^{4} \Sigma^{-}$state correlates

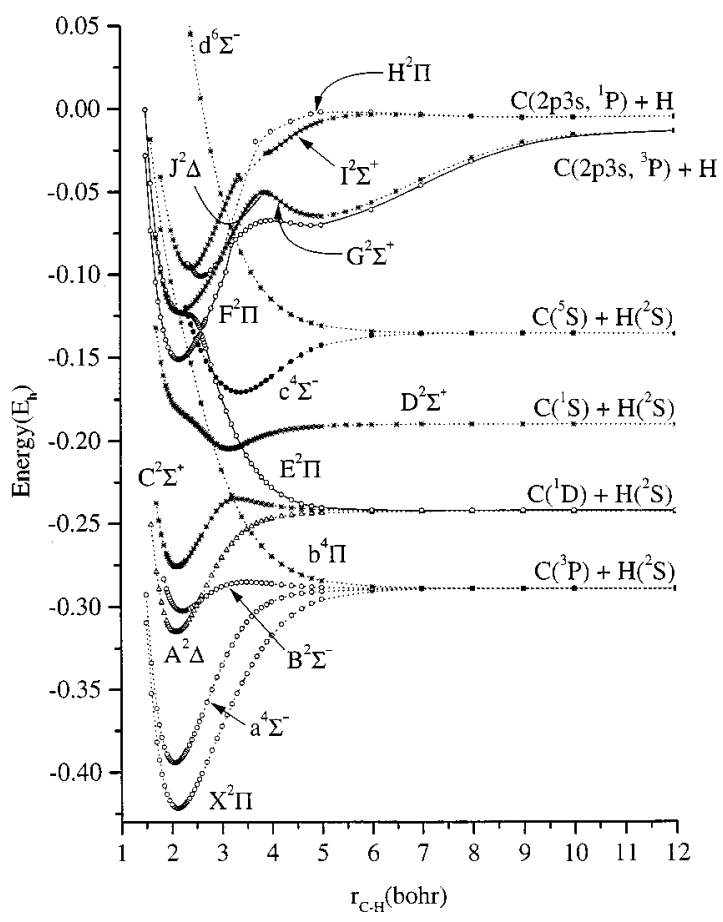

FIG. 1. Potential energy curves of the lowest 11 valence and 4 Rydberg states of $\mathrm{CH}$. All energies have been shifted by +38.00 hartree. to the ${ }^{5} S\left(2 s^{1} 2 p^{3}\right)$ carbon state. Despite their large energy separation $\left(T_{e}=140.2 \mathrm{kcal} / \mathrm{mol}\right)$ our findings indicate that these two quartets interact substantially. In other words, the ${ }^{5} S$ carbon state plays a prominent role in the bonding mechanism of the $a^{4} \Sigma^{-}$state. The CASSCF atomic equilibrium and infinite separation Mulliken distributions are $(\mathrm{C} / \mathrm{H})$

$$
\begin{aligned}
& r_{e}: \quad 2 s^{1.42} 2 p_{z}^{0.81} 2 p_{x}^{0.98} 2 p_{y}^{0.98} 3 d^{0.03} / 1 s^{0.72} 2 p^{0.03}, \\
& r_{\infty}: \quad 2 s^{1.95} 2 p_{z}^{0.04} 2 p_{x}^{1.0} 2 p_{y}^{1.0} 3 d^{0.01} / 1 s^{1.0} .
\end{aligned}
$$

We see that upon interaction $0.5 e^{-}$from the $2 s_{\mathrm{C}}$ and $0.3 e^{-}$ from the $1 s_{\mathrm{H}}$ have been promoted to the $2 p_{z}$ orbital of $\mathrm{C}$. We claim that the in situ $\mathrm{C}$ atom finds itself to a considerable degree in the ${ }^{5} S$ excited state, with a corresponding CAS leading configuration

$$
\left|a^{4} \Sigma^{-}\right\rangle=0.99\left|1 \sigma^{2} 2 \sigma^{2} 3 \sigma^{1} 1 \pi_{x}^{1} 1 \pi_{y}^{1}\right\rangle,
$$

and the following vbL picture of the molecule:

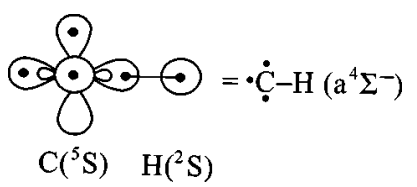

The $a^{4} \Sigma^{-}$state was first observed in 1970 by Feldmann ${ }^{142}$ using laser photoelectron spectroscopy of $\mathrm{CH}^{-}$. Kasdan et al. ${ }^{143}$ in 1975 obtained a $T_{0}=0.742 \pm 0.008 \mathrm{eV}=17.11$ $\pm 0.18 \mathrm{kcal} / \mathrm{mol}$, which combined with the experimental $D_{0}$ of the $X^{2} \Pi$ state $(3.465 \mathrm{eV})^{48}$ gives $D_{0}=2.723 \pm 0.01 \mathrm{eV}$ $=62.80 \pm 0.23 \mathrm{kcal} / \mathrm{mol}$ for the $a^{4} \Sigma^{-}$state. Our MRCI $T_{0}$ $\left(=T_{e}+\Delta \omega_{e} / 2-\Delta \omega_{e} \chi_{e} / 4\right)$ and $D_{0}\left(=D_{e}-\omega_{e} / 2+\omega_{e} \chi_{e} / 4\right)$ are 17.53 and $61.65 \mathrm{kcal} / \mathrm{mol}$, respectively (Tables III and IV). The discrepancy of about $1 \mathrm{kcal} / \mathrm{mol}$ in $D_{0}$ between experiment and theory can be attributed to corresponding differences of $D_{e}$ of $X^{2} \Pi(0.57 \mathrm{kcal} / \mathrm{mol})$ and of $T_{0}(0.42 \mathrm{kcal} / \mathrm{mol})$, which amount to $0.99 \mathrm{kcal} / \mathrm{mol}$. Nelis et al. ${ }^{144}$ employing a laser magnetic resonance method reported an experimental (vibrationally averaged) bond distance $r_{0}=1.09767 \AA$ in fair agreement with our $r_{e}$ $=1.0892 \AA$. Notice that this is the shortest bond distance of all examined states. Corresponding theoretical values by Lie et al. ${ }^{175}$ are: $T_{0}=15.43 \mathrm{kcal} / \mathrm{mol}, D_{0}=60.88 \mathrm{kcal} / \mathrm{mol}$, and $r_{e}=1.0864 \AA$.

The $c^{4} \Sigma^{-}$state has never been observed experimentally. The only theoretical investigation we are aware of is the SCF calculation of Liu and Verhaegen ${ }^{170}$ at $r=2.9 \mathrm{bohr}$ $(=1.535 \AA)$ with semiempirical correlation corrections. They gave a $T_{e}\left(c^{4} \Sigma^{-} \leftarrow X^{2} \Pi\right)=200 \mathrm{kcal} / \mathrm{mol}$.

The PEC of this state is illustrated in Fig. 1, and from Table III we see that $T_{e}\left(c^{4} \Sigma^{-} \leftarrow X^{2} \Pi\right)=157.38 \mathrm{kcal} / \mathrm{mol}$, $D_{e}=22.31 \mathrm{kcal} / \mathrm{mol}$, with respect to $\mathrm{C}\left({ }^{5} S\right)+\mathrm{H}\left({ }^{2} S\right)$, and $r_{e}$ $=1.7866 \AA$. The leading CASSCF configurations are

$$
\begin{aligned}
\left|c^{4} \Sigma^{-}\right\rangle= & -0.55\left|1 \sigma^{2} 2 \sigma^{2} 3 \sigma^{1} 1 \pi_{x}^{1} 1 \pi_{y}^{1}\right\rangle \\
& +0.51\left|1 \sigma^{2} 2 \sigma^{1} 3 \sigma^{2} 1 \pi_{x}^{1} 1 \pi_{y}^{1}\right\rangle \\
& -0.40\left|1 \sigma^{2} 2 \bar{\sigma}^{1} 3 \sigma^{1} 4 \sigma^{1} 1 \pi_{x}^{1} 1 \pi_{y}^{1}\right\rangle \\
& -0.26\left|1 \sigma^{2} 2 \sigma^{2} 4 \sigma^{1} 1 \pi_{x}^{1} 1 \pi_{y}^{1}\right\rangle,
\end{aligned}
$$


with CAS equilibrium Mulliken populations $(\mathrm{C} / \mathrm{H})$

$$
2 s^{1.17} 2 p_{z}^{0.83} 2 p_{x}^{1.0} 2 p_{y}^{1.0} / 1 s^{0.98} \text {. }
$$

The -0.55 component above corresponds to the main CF of the $a^{4} \Sigma^{-}$state, while the 0.51 and -0.40 components correspond to the asymptotes of $a^{4} \Sigma^{-}\left({ }^{3} P+{ }^{2} S\right)$ and $c^{4} \Sigma^{-}\left({ }^{5} S\right.$ $\left.+{ }^{2} S\right)$, respectively.

\section{The $A^{2} \Delta$ state}

This state traces its ancestry to $\mathrm{C}\left({ }^{1} D\right)+\mathrm{H}\left({ }^{2} S\right)$, as shown in Fig. 1. Its CASSCF wave-function at equilibrium and its Mulliken distributions at $r_{e}$ and $r_{\infty}$ are as follows:

$$
\begin{aligned}
& \left|A^{2} \Delta\right\rangle \approx 0.69\left\{\left|1 \sigma^{2} 2 \sigma^{2} 3 \sigma^{1} 1 \pi_{x}^{2}\right\rangle-\left|1 \sigma^{2} 2 \sigma^{2} 3 \sigma^{1} 1 \pi_{y}^{2}\right\rangle\right\}, \\
& r_{e}: \quad 2 s^{1.55} 2 p_{z}^{0.73} 2 p_{x}^{0.97} 2 p_{y}^{0.97} 3 d^{0.05} / 1 s^{0.67} 2 p^{0.05}, \\
& r_{\infty}: \quad 2 s^{1.93} 2 p_{z}^{0.05} 2 p_{x}^{1.0} 2 p_{y}^{1.0} 3 d^{0.03} / 1 s^{1.0} .
\end{aligned}
$$

It is obvious that $0.38 e^{-}$from $2 s_{\mathrm{C}}$ and $0.28 e^{-}$from $1 s_{\mathrm{H}}$ are transferred to the $2 p_{z, \mathrm{C}}$ orbital $(0.38+0.28+0.05=0.71)$. We observe that the in situ $\mathrm{C}$ atom is in a $s^{1} p^{3}$ valence excited state, which by symmetry cannot be other than the ${ }^{3} D\left(2 s^{1} 2 p^{3}\right)$ state, lying $7.942 \mathrm{eV}$ above the ground ${ }^{3} P$ state (Table II). It is remarkable that the interaction of $\mathrm{C}\left({ }^{1} D\right)$ $+\mathrm{H}\left({ }^{2} S\right)$ to form a $A^{2} \Delta$ state has as a result the excitation of C to the ${ }^{3} D$ state, $6.68 \mathrm{eV}$ above the ${ }^{1} D$ state. From Tables I and III we see that our $T_{e} \quad\left(A^{2} \Delta \leftarrow X^{2} \Pi\right)$ $=66.89 \mathrm{kcal} / \mathrm{mol}, r_{e}=1.1056 \AA, D_{e}=45.54 \mathrm{kcal} / \mathrm{mol}$, and our dipole moment $\mu=0.8434 \mathrm{D}$ are in excellent agreement with the experimental values. ${ }^{48,83,86,74}$ However, considering the strong involvement $(\sim 70 \%)$ of the ${ }^{3} D$ state in the $\sigma$-bond formation, the intrinsic bond strength of this state is 153 $\mathrm{kcal} / \mathrm{mol}(6.68 \times 0.70 \mathrm{eV}+45.5 \mathrm{kcal} / \mathrm{mol})$. The values of Lie et al. ${ }^{175}$ are also in good agreement with the experiment $\left(r_{e}=1.1023 \AA, \quad T_{e}=67.36 \mathrm{kcal} / \mathrm{mol}, \quad\right.$ and $D_{e}$ $=43.82 \mathrm{kcal} / \mathrm{mol})$. A vbL picture conforming to the discussion above is

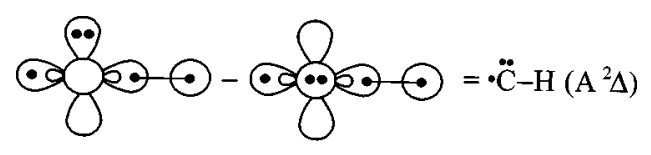

\section{The $B^{2} \Sigma^{-}$state}

This weakly bound state is depicted in Fig. 1 and correlates to the ground $\mathrm{C}\left({ }^{3} P\right)+\mathrm{H}\left({ }^{2} S\right)$. The leading CASSCF configurations at equilibrium and the corresponding Mulliken populations are

$$
\begin{aligned}
&\left|B^{2} \Sigma^{-}\right\rangle \approx 0.79\left|1 \sigma^{2} 2 \sigma^{2} 3 \bar{\sigma}^{1} 1 \pi_{x}^{1} 1 \pi_{y}^{1}\right\rangle \\
&-0.40\left\{\left|1 \sigma^{2} 2 \sigma^{2} 3 \sigma^{1} 1 \pi_{x}^{1} 1 \bar{\pi}_{y}^{1}\right\rangle\right. \\
&\left.+\left|1 \sigma^{2} 2 \sigma^{2} 3 \sigma^{2} 1 \pi_{x}^{1} 1 \bar{\pi}_{y}^{1}\right\rangle\right\}, \\
& 2 s^{1.74} 2 p_{z}^{0.55} 2 p_{x}^{0.98} 2 p_{y}^{0.98} 3 d^{0.03} / 1 s^{0.68} 2 p^{0.03} .
\end{aligned}
$$

The following vbL diagram suggests that the two atoms are held together by a half $\sigma$-bond.

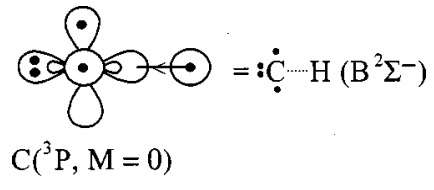

At 3.5 bohr our MRCI calculations reveal an energy barrier of $2.32 \mathrm{kcal} / \mathrm{mol}$, first observed experimentally at about 4 bohr by Herzberg and Johns. ${ }^{30}$ We assume that this is due to the participation of the ${ }^{3} D\left(2 s^{1} 2 p^{3}\right)$ excited state of $\mathrm{C}$, as evinced by the population analysis. As Table I shows, Herzberg and Johns ${ }^{30}$ and Kepa et al. ${ }^{89}$ report an $r_{e}$ $=1.1640 \AA$ while in the Huber and Herzberg compilation ${ }^{48}$ $r_{e}=1.1975 \AA$ A In Table III we report a $r_{e}=1.1768 \AA$ as well as $T_{e}=74.74 \mathrm{kcal} / \mathrm{mol}$ and $D_{e}=8.59 \mathrm{kcal} / \mathrm{mol}$ which compare well with the respective experimental values of 74.51 and $9.43 \mathrm{kcal} / \mathrm{mol}$ [Tables I and III, using $D_{e}(X)-T_{e}(B)$ ]. The corresponding theoretical values of Lie et al. ${ }^{175}$ are $r_{e}$ $=1.1727 \AA, T_{e}=75.09 \mathrm{kcal} / \mathrm{mol}$, and $D_{e}=5.30 \mathrm{kcal} / \mathrm{mol}$.

\section{E. The $b^{4}$ II state}

As it is shown in Fig. 1, this is the first repulsive state correlating to the ground state fragments. Although not apparent from its plot, this state possesses a calculated van der Waals minimum of $4.5 \mathrm{~cm}^{-1}$ at about $9.0 \mathrm{bohr}$.

\section{F. The $C^{2} \Sigma^{+}$state}

The Hartree-Fock ${ }^{1} D(M=0)$ wavefunction of $\mathrm{C}$ is

$$
\left|{ }^{1} D\right\rangle=(1 / 6)^{1 / 2}\left\{2\left|2 s^{2} 2 p_{z}^{2}\right\rangle-\left|2 s^{2} 2 p_{x}^{2}\right\rangle-\left|2 s^{2} 2 p_{y}^{2}\right\rangle\right\} .
$$

As $\mathrm{H}\left({ }^{2} S\right)$ approaches $\mathrm{C}\left({ }^{1} D\right)$ from infinity the interaction is repulsive at first, leading eventually to an energy barrier of $4.66 \mathrm{kcal} / \mathrm{mol}$ at about $3.3 \mathrm{bohr}$ (Fig. 1). Lie et al. ${ }^{175}$ have calculated its height to be $6.6 \mathrm{kcal} / \mathrm{mol}$ at about $3.3 \mathrm{bohr}$, and it has also been observed experimentally. ${ }^{30}$ As the interatomic distance approaches equilibrium, the strong interaction with the $D^{2} \Sigma^{+}$state induces a decrease in the $p_{z}$ electronic density accompanied by a simultaneous increase in the densities of $p_{x}$ and $p_{y}$. At equilibrium, the leading CAS configurations and the atomic Mulliken CAS distributions at $r_{e}$ and $r_{\infty}$ are

$$
\begin{gathered}
\left|C^{2} \Sigma^{+}\right\rangle \approx 0.69\left\{\left|1 \sigma^{2} 2 \sigma^{2} 3 \sigma^{1} 1 \pi_{x}^{2}\right\rangle\right. \\
\left.+\left|1 \sigma^{2} 2 \sigma^{2} 3 \sigma^{1} 1 \pi_{y}^{2}\right\rangle\right\}, \\
r_{e}: \quad 2 s^{1.54} 2 p_{z}^{0.72} 2 p_{x}^{0.98} 2 p_{y}^{0.98} 3 d^{0.02} / 1 s^{0.67} 2 p^{0.07}, \\
r_{\infty}: \quad 2 s^{1.93} 2 p_{z}^{1.47} 2 p_{x}^{0.28} 2 p_{y}^{0.28} 3 d^{0.03} / 1 s^{1.0} .
\end{gathered}
$$

The distributions and the CAS wavefunctions above suggest the following bonding diagram:

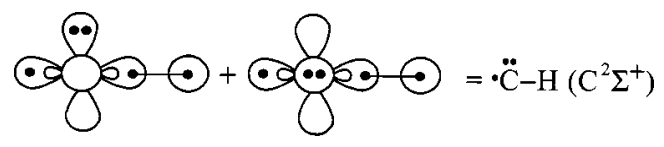

According to Tables I and III the experimental values $^{30,48}$ of $D_{e}=21.68 \mathrm{kcal} / \mathrm{mol}$ (with respect to the adiabatic products), $r_{e}=1.1143 \AA$ and $T_{e}=90.93 \mathrm{kcal} / \mathrm{mol}$ are in good agreement with our MRCI results of $20.98 \mathrm{kcal} / \mathrm{mol}$, 
$1.1164 \AA$ A, and $91.85 \mathrm{kcal} / \mathrm{mol}$, respectively. The corresponding values of Lie et al. ${ }^{175}$ are $18.0 \mathrm{kcal} / \mathrm{mol}, 1.1113 \AA$, and $92.72 \mathrm{kcal} / \mathrm{mol}$. Notice that this is the last state that Lie et al. have calculated.

\section{G. The $D^{2} \Sigma^{+}$state}

The $D^{2} \Sigma^{+}$PEC is illustrated in Fig. 1 and correlates to the $\mathrm{C}\left({ }^{1} S\right)+\mathrm{H}\left({ }^{2} S\right)$ fragments. Its rather "irregular" shape is due to a strong interaction with the $C^{2} \Sigma^{+}$and $G^{2} \Sigma^{+}$states. The $\mathrm{C}\left({ }^{1} S\right)$ state is described by

$$
\left|{ }^{1} S\right\rangle=(1 / 3)^{1 / 2}\left\{\left|2 s^{2} 2 p_{z}^{2}\right\rangle+\left|2 s^{2} 2 p_{x}^{2}\right\rangle+\left|2 s^{2} 2 p_{y}^{2}\right\rangle\right\} .
$$

The leading CAS configurations at equilibrium are

$$
\begin{aligned}
\left|D^{2} \Sigma^{+}\right\rangle \approx & 0.83\left|1 \sigma^{2} 2 \sigma^{2} 3 \sigma^{2} 4 \sigma^{1}\right\rangle \\
& -0.29\left|1 \sigma^{2} 2 \sigma^{2} 3 \sigma^{1}\left(1 \pi_{x}^{2}+1 \pi_{y}^{2}\right)\right\rangle .
\end{aligned}
$$

This is essentially the same as the asymptotic CAS wavefunction of the $C^{2} \Sigma^{+}$state, namely:

$$
\begin{aligned}
\left|C^{2} \Sigma^{+}\right\rangle \approx & 0.78\left|2 s^{2} 2 p_{z}^{2}\right\rangle\left|1 s^{1}\right\rangle \\
& -0.40\left|2 s^{2}\left(2 p_{x}^{2}+2 p_{y}^{2}\right)\right\rangle\left|1 s^{1}\right\rangle .
\end{aligned}
$$

As the system moves past the equilibrium point, an intense valence-Rydberg mixing takes place at $2.8 \mathrm{bohr}$ with the $G^{2} \Sigma^{+}$state, which correlates to the carbon Rydberg ${ }^{3} P\left(2 p^{1} 3 s^{1}\right)$ state. Although the $D^{2} \Sigma^{+} \leftarrow X^{2} \Pi$ transition is symmetry allowed, it has not been observed spectroscopically, probably due to unfavorable Franck-Condon factors.

As shown in Table III, at the MRCI level of theory we have obtained $r_{e}=1.6635 \AA, D_{e}=9.35 \mathrm{kcal} / \mathrm{mol}$, and $T_{e}$ $=136.11 \mathrm{kcal} / \mathrm{mol}$.

\section{H. The $d^{6} \Sigma^{-}$state}

This is a purely repulsive state (Fig. 1) originating from the ${ }^{5} S\left(2 s^{1} 2 p^{3}\right)$ valence state of $\mathrm{C}$, as is the $c^{4} \Sigma^{-}$state (vide supra). It presents a van der Waals attraction of $3.15 \mathrm{~cm}^{-1}$ at about 9 bohr.

\section{The $E^{2} \Pi, F^{2} \Pi$, and $H^{2} \Pi$ states}

The $E, F$, and $H^{2} \Pi$ states correlate to the ${ }^{1} D\left(2 s^{2} 2 p^{2}\right)$, ${ }^{3} P$ and ${ }^{1} P\left(2 s^{2} 2 p^{1} 3 s^{1}\right)$ Rydberg states of the $\mathrm{C}$ atom, respectively. These carbon states span an energy range of 6.42 eV (Table II). The three excited ${ }^{2} \Pi$ states exhibit avoided crossings at different interatomic distances as illustrated in Fig. 1. The avoided crossing between the $E$ and $F^{2} \Pi$ states occurs at $2.58 \mathrm{bohr}$ giving the $E$ state a volcanic type appearance with a local minimum at 2.16 bohr. As the $\mathrm{H}$ atom approaches from infinity, it is confronted by the ${ }^{1} D$ electron distribution of $\mathrm{C}$ given by $(1 / 2)^{1 / 2}\left\{\left|2 s^{2} 2 p_{x}{ }^{1} 2 \bar{p}_{z}{ }^{1}\right\rangle\right.$ $\left.-\left|2 s^{2} 2 \bar{p}_{x}{ }^{1} 2 p_{z}{ }^{1}\right\rangle\right\}$. This is an improper distribution for attractive interaction due to the singlet coupling of the $p$ electrons, as opposed to the triplet coupling which leads to the ground state. At the avoided crossing the $E$ state exchanges electron distributions with the descending $F$ state, thus creating the local minimum mentioned above. The generated energy barrier of the $E$ state (the lower of the split levels at the avoided crossing) is $9.69 \mathrm{kcal} / \mathrm{mol}$ from the local mini- mum, which has a $r_{e}=1.1437 \AA$ and a $T_{e}$ $=169.68 \mathrm{kcal} / \mathrm{mol}$. The corresponding experimental parameters $^{48}$ are $r_{e}=1.15 \AA$, and $T_{e}=172.7 \mathrm{kcal} / \mathrm{mol}$. Notice that the state labeled as $D^{2} \Pi$ in the experimental work ${ }^{30,48}$ is the $E^{2} \Pi$ state in our work due to the intervening unobserved $D^{2} \Sigma^{+}$state.

The leading CAS configurations and the corresponding Mulliken distributions at the local minimum are

$$
\begin{aligned}
\left|E^{2} \Pi\right\rangle \approx & 0.92\left|1 \sigma^{2} 2 \sigma^{2} 1 \pi_{x}^{1} 1 \pi_{y}^{2}\right\rangle-0.15\left|1 \sigma^{2} 3 \sigma^{2} 1 \pi_{x}^{1} 1 \pi_{y}^{2}\right\rangle \\
& 2 s^{1.47} 2 p_{z}^{0.14} 2 p_{x}^{0.98} 2 p_{y}^{1.83} 3 d^{0.04} / 1 s^{0.47} 2 p^{0.06},
\end{aligned}
$$

corresponding to the following vbL bonding diagram:

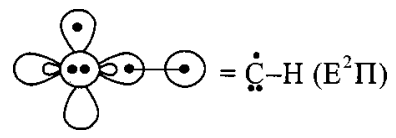

Upon interaction a total of $0.5 e^{-}$are transferred from the $\mathrm{H}$ to the $\mathrm{C}$ atom.

The local minimum of $E^{2} \Pi$ mirrors the ${ }^{3} D\left(2 s^{1} 2 p^{3}, M\right.$ $= \pm 1)$ valence carbon state, $8.0 \mathrm{eV}$ above its ground ${ }^{3} P$ state, as evidenced from the ${ }^{3} \mathrm{D}$ configuration:

$$
\begin{aligned}
{ }^{2} D & \left(2 s^{1} 2 p^{3}, M= \pm 1\right) \\
& =(1 / 2)^{1 / 2}\left\{\left|2 s^{1} 2 p_{x}^{1} 2 p_{y}^{2}\right\rangle-\left|2 s^{1} 2 p_{x}^{1} 2 p_{z}^{2}\right\rangle\right\} .
\end{aligned}
$$

The removal of the $2 p_{z}^{2}$ component, detrimental to attractive interaction, necessitates the involvement of the following valence state of C, not shown in Fig. 1 and lying $1.39 \mathrm{eV}$ above the ${ }^{3} D$ state:

$$
\begin{aligned}
& { }^{2} P\left(2 s^{1} 2 p^{3}, M= \pm 1\right) \\
& \quad=(1 / 2)^{1 / 2}\left\{\left|2 s^{1} 2 p_{x}^{1} 2 p_{y}^{2}\right\rangle+\left|2 s^{1} 2 p_{x}^{1} 2 p_{z}^{2}\right\rangle\right\} .
\end{aligned}
$$

This means that the local minimum corresponds to an intrinsic bond strength (with respect to the ${ }^{3} D$ state) of $100 \mathrm{kcal} /$ mol.

The $F^{2} \Pi$ state has a local minimum around 4.8 bohr with an energy barrier of $1.9 \mathrm{kcal} / \mathrm{mol}$ and a global wedgelike minimum at $r_{x}=2.6 \mathrm{bohr}=1.375 \AA$, which is the point of avoided crossing with the $E^{2} \Pi$ state (vide supra). At the MRCI level this "minimum" (the higher of the split levels) is $75.22 \mathrm{kcal} / \mathrm{mol}$, and it lies $181.57 \mathrm{kcal} / \mathrm{mol}$ above the ground state (" $T_{e}$,"). Both minima are with respect to the asymptotic $\mathrm{C}\left({ }^{3} P\right)+\mathrm{H}\left({ }^{2} S\right)$ level. The corresponding experimental values, ${ }^{48}$ also given in Tables I and III are: $r_{e}$ $=1.20 \AA$ and $T_{e}=187.6 \mathrm{kcal} / \mathrm{mol}$ (in Ref. 48 this state is designated as $\left.E^{2} \Pi\right)$.

A state of ${ }^{2} \Pi$ symmetry correlating to the ${ }^{3} D$ term of C lends its character to the $H^{2} \Pi$ state at around $3.2 \mathrm{bohr}$, which in turn passes its character to the $F^{2} \Pi$ state via an avoided crossing at about $3.1 \mathrm{bohr}$ (Fig. 1). As a result, the minimum of the $H^{2} \Pi$ state can be considered as the continuation of the $F^{2} \Pi$ state. These observations are corroborated by the main CAS configurations at the global "minimum" of the $F$ state: 


$$
\begin{aligned}
\left|F^{2} \Pi\right\rangle \approx & 0.72\left|1 \sigma^{2} 2 \sigma^{2} 3 \sigma^{1} 4 \sigma^{1} 1 \bar{\pi}_{x}^{1}\right\rangle \\
& -0.30\left|1 \sigma^{2} 2 \sigma^{2} 3 \sigma^{1} 4 \bar{\sigma}^{1} 1 \pi_{x}^{1}\right\rangle \\
& -0.46\left|1 \sigma^{2} 3 \sigma^{2} 1 \pi_{x}^{1} 1 \pi_{y}^{2}\right\rangle .
\end{aligned}
$$

The 0.72 and -0.30 components express the repulsive part of the $E^{2} \Pi$ state, while the -0.46 component reflects the attractive part of the $F^{2} \Pi$ state. The shoulder of this state at about 2.4 bohr, just to the left of the avoided crossing, is caused by an interaction with the $H^{2} \Pi$ state. There are no spectroscopic data for this last state. For technical reasons (convergence problems at the $\mathrm{CI}$ level) we were unable to calculate a full $H^{2} \Pi$ curve (Fig. 1). Our MRCI results for this state (Table III) are: $D_{e}=61.0 \mathrm{kcal} / \mathrm{mol}$ (with respect to the asymptotic products), $\quad r_{e}=1.3762 \AA$ and $T_{e}$ $=201.1 \mathrm{kcal} / \mathrm{mol}$.

\section{J. The $G^{2} \Sigma^{+}$state}

The PEC of this state is depicted in Fig. 1 and correlates adiabatically to the ${ }^{3} P\left(2 p^{1} 3 s^{1}\right)$ Rydberg state of C. It has two minima, a local one at about 5.0 bohr with $D_{e}$ $=32.7 \mathrm{kcal} / \mathrm{mol}$, and a global one at $r_{e}=1.1482 \AA$ with $D_{e}$ $=69.30 \mathrm{kcal} / \mathrm{mol}$. The barrier between them is $9.1 \mathrm{kcal} / \mathrm{mol}$ measured from the local minimum and sustains at least three vibrational modes (Table IV). It is a result of an avoided crossing with the $I^{2} \Sigma^{+}$state (vide infra); this is supported by the leading CASSCF configurations at equilibrium:

$$
\begin{aligned}
\left|G^{2} \Sigma^{+}\right\rangle \approx & -0.78\left|1 \sigma^{2} 2 \sigma^{2} 3 \sigma^{2} 5 \sigma^{1}\right\rangle \\
& -0.44\left|1 \sigma^{2} 2 \sigma^{2} 3 \sigma^{2} 4 \sigma^{1}\right\rangle \\
& +0.35\left|1 \sigma^{2} 2 \sigma^{2} 3 \sigma^{2} 6 \sigma^{1}\right\rangle .
\end{aligned}
$$

The -0.44 component reflects the $D^{2} \Sigma^{+}$state (valenceRydberg mixing) while the 0.35 component corresponds to the $I^{2} \Sigma^{+}$state.

The experimental values ${ }^{48}$ are $r_{e}=1.221 \AA$ and $T_{e}$ $=188.55 \mathrm{kcal} / \mathrm{mol}$, while our MRCI results are $r_{e}$ $=1.1482 \AA$ and $T_{e}=187.36 \mathrm{kcal} / \mathrm{mol}$ (Table III). Notice that in Ref. 30, the $G$ state is referred to as $F$ state.

\section{K. The $I^{2} \Sigma^{+}$state}

This state is illustrated in Fig. 1 and correlates to the ${ }^{1} P\left(2 p^{1} 3 s^{1}\right)$ Rydberg carbon state. Due to technical reasons (convergence problems at the CI level) a part of the PEC from 3.35 to 3.85 bohr has not been completed. The leading CAS configurations at equilibrium are:

$$
\begin{aligned}
\left|I^{2} \Sigma^{+}\right\rangle \approx & 0.81\left|1 \sigma^{2} 2 \sigma^{2} 3 \sigma^{2} 6 \sigma^{1}\right\rangle \\
& +0.41\left|1 \sigma^{2} 2 \sigma^{2} 3 \sigma^{2} 4 \sigma^{1}\right\rangle \\
& +0.19\left|1 \sigma^{2} 2 \sigma^{2} 3 \sigma^{2} 5 \sigma^{1}\right\rangle .
\end{aligned}
$$

The 0.41 component represents the valence-Rydberg mixing with the $D^{2} \Sigma^{+}$state and the 0.19 component reflects the mixing with the $G^{2} \Sigma^{+}$state.

Our MRCI results, listed in Table III, are $D_{e}$ $=57.85 \mathrm{kcal} / \mathrm{mol}, r_{e}=1.2639 \AA$, and $T_{e}=204.15 \mathrm{kcal} / \mathrm{mol}$. There are no experimental results in the literature for this state.

\section{The $J^{2} \Delta$ state}

Part of the $J^{2} \Delta$ state around equilibrium is depicted in Fig. 1; it stems from the ${ }^{3} D$ valence state of C. No experimental values exist in the literature. Our MRCI results, listed in Table III, are: $D_{e}=48.9 \mathrm{kcal} / \mathrm{mol}, r_{e}=1.666 \AA$, and $T_{e}$ $=221 \mathrm{kcal} / \mathrm{mol}$.

Although there are no experimental results for the $H^{2} \Pi$, $I^{2} \Sigma^{+}$, and $J^{2} \Delta$ states, an unidentified state of either ${ }^{2} \Pi$, ${ }^{2} \Sigma^{+}$, or ${ }^{2} \Delta$ symmetry has been reported ${ }^{30,48}$ with $T_{e}$ $=213 \mathrm{kcal} / \mathrm{mol}$.

\section{SYNOPSIS}

Using large, correlation consistent basis sets and MRCI $(\mathrm{CASSCF}+1+2)$ methods, we have computed PECs for 15 states of the $\mathrm{CH}$ radical, spanning an energy range of $9.6 \mathrm{eV}$. Our results can be considered in quantitative agreement with existing experimental findings. In particular, for the $X^{2} \Pi$ state (after correction for core correlation effects), our $D_{e}$ value is smaller than the experimental one by $0.43 \mathrm{kcal} / \mathrm{mol}$ $\left(=150 \mathrm{~cm}^{-1}\right)$ and our $r_{e}$ value smaller by $0.0014 \AA$ compared to Ref. 86 and larger by 0.00034 compared to Ref. 147. It is interesting that the bond lengths of all bound states reported in Table III are improved upon applying a uniform $0.002 \AA$ contraction due to core-valence correlation effects. ${ }^{233,234}$

In general, $0.2-0.5 e^{-}$are transferred from $\mathrm{H}$ to $\mathrm{C}$ upon molecule formation. Dipole moments range from $0.16 \mathrm{D}\left(I^{2} \Sigma^{+}\right)$to a remarkably high value of $6.17 \mathrm{D}$ $\left(G^{2} \Sigma^{+}\right)$. Finally, the multireference Davidson correction allows us to claim that for the first ten states, valence correlation has been extracted to within 2 mhartree.

Note added in proof. While in press X. Li and Y.-P. Lee [J. Chem. Phys. 111, 4942 (1999)] reported a $T_{0}\left(D^{2} \Pi\right.$ $\left.\leftarrow X^{2} \Pi\right)=58980.592(53) \mathrm{cm}^{-1}$, in excellent agreement with our $T_{0}=T_{e}+\Delta \omega_{e} / 2=169.68 \mathrm{kcal} / \mathrm{mol}+\left(-54.0 \mathrm{~cm}^{-1}\right)$ $=59292 \mathrm{~cm}^{-1}$. Please note that the $D^{2} \Pi$ state of $\mathrm{Li}$ and Lee is referred to as $E^{2} \Pi$ in the present paper (see text).

\section{ACKNOWLEDGMENT}

The financial support of the National and Kapodistrian University of Athens through its Special Research Account for Basic Research is greatly appreciated.

\footnotetext{
${ }^{1}$ T. Heurlinger, Ph.D. thesis, University of Lund, 1918.

${ }^{2}$ T. Heurlinger and E. Hulthen, Z. Wiss. Photogr. Photophys. Photochem. 18, 241 (1919).

${ }^{3}$ E. Hulthen, Z. Phys. 11, 284 (1922).

${ }^{4}$ A. Kratzer, Z. Phys. 23, 298 (1924).

${ }^{5}$ R. S. Mulliken, Phys. Rev. 30, 785 (1927); Rev. Mod. Phys. 3, 89 (1931).

${ }^{6}$ T. Hori, Z. Phys. 59, 91 (1929).

${ }^{7}$ T. Heimer, Z. Phys. 78, 771 (1932).

${ }^{8}$ T. Shidei, Jpn. J. Phys. 11, 23 (1936).

${ }^{9}$ L. Gerö, Z. Phys. 117, 709 (1941); 118, 27 (1941).

${ }^{10}$ A. McKellar, Publ. Dom. Astrophys. Obs. Victoria BC 7, 251 (1941).

${ }^{11}$ G. Herzberg, Spectra of Diatomic Molecules, 2nd ed. (Van Nostrand, New York, 1950).

${ }^{12}$ G. Porter, Discuss. Faraday Soc. 10, 108 (1951).

${ }^{13}$ R. A. Durie, Proc. Phys. Soc. Jpn. 65, 125 (1952).

${ }^{14}$ R. G. W. Norrish, G. Porter, and B. A. Thrush, Proc. R. Soc. London, Ser. A 216, 165 (1953).

${ }^{15}$ N. H. Kiess and H. P. Broida, Astrophys. J. 123, 166 (1956).
} 
${ }^{16}$ G. Herzberg and J. Shoosmith, Nature (London) 183, 1801 (1959).

${ }^{17}$ R. G. Bennett and F. W. Dalby, J. Chem. Phys. 32, 1716 (1960).

${ }^{18}$ A. M. Bass and H. P. Broida, National Bureau of Standards Monograph No. 24 (U.S. Gov. Printing Office, Washington, DC, 1961).

${ }^{19}$ G. Herzberg, Proc. R. Soc. London, Ser. A 262, 291 (1961).

${ }^{20}$ P. G. Wilkinson, Astrophys. J. 138, 778 (1963).

${ }^{21}$ R. H. Garstang, Proc. Phys. Soc. Jpn. 82, 545 (1963).

${ }^{22}$ R. G. Brewer and F. L. Kester, J. Chem. Phys. 40, 812 (1964).

${ }^{23}$ M. Jeunehomme and A. B. F. Duncan, J. Chem. Phys. 41, 1692 (1965).

${ }^{24}$ A. E. Douglas and G. A. Elliott, Can. J. Phys. 43, 496 (1965).

${ }^{25}$ D. H. Phelps and F. W. Dalby, Phys. Rev. Lett. 16, 3 (1966).

${ }^{26}$ G. Herzberg and J. W. C. Johns, Proc. R. Soc. London, Ser. A 295, 107 (1966).

${ }^{27}$ E. H. Fink and K. H. Weldge, J. Chem. Phys. 46, 4315 (1967).

${ }^{28}$ M. J. Linevsky, J. Chem. Phys. 47, 3485 (1967).

${ }^{29}$ J. E. Hesser and B. L. Lutz, Phys. Rev. Lett. 20, 363 (1968).

${ }^{30}$ G. Herzberg and J. W. C. Johns, Astrophys. J. 158, 399 (1969).

${ }^{31}$ J. E. Hesser and B. L. Lutz, Astrophys. J. 159, 703 (1970).

${ }^{32}$ W. H. Smith, J. Chem. Phys. 54, 1384 (1971).

${ }^{33}$ K. M. Evenson, H. E. Radford, and M. M. Moran, Jr., Appl. Phys. Lett. 18, 426 (1971).

${ }^{34}$ K. M. Baird and H. Bredohl, Astrophys. J. Lett. 169, L83 (1971).

${ }^{35}$ L. M. DeBall, J. Quant. Spectrosc. Radiat. Transf. 12, 1701 (1972).

${ }^{36}$ N. Elander and W. H. Smith, Astrophys. J. 184, 663 (1973).

${ }^{37}$ P. Erman, Nucl. Instrum. Methods 110, 471 (1973).

${ }^{38}$ N. H. Brooks and W. H. Smith, Astrophys. J. 194, 513 (1974).

${ }^{39}$ O. E. H. Rydbeck, J. Ellder, M. W. Irvine, A. Sume, and A. Hjalmarson, Astron. Astrophys. 34, 479 (1974).

${ }^{40}$ S. W. Jørgensen and G. Sørensen, J. Chem. Phys. 62, 2550 (1975).

${ }^{41}$ R. A. Anderson, J. Peacher, and D. M. Wilcox, J. Chem. Phys. 63, 5287 (1975).

${ }^{42}$ R. W. B. Pearse and A. G. Gaydon, The Identification of Molecular Spectra, 4th ed. (Chapman and Hall, London, 1976).

${ }^{43}$ J. Brzozowski, P. Bunker, N. Elander, and P. Erman, Astrophys. J. 207, 414 (1976).

${ }^{44}$ J. Carozza and R. A. Anderson, J. Opt. Soc. Am. 67, 118 (1977).

${ }^{45}$ D. Cvejanović, A. Adams, and G. C. King, J. Phys. B 11, 1653 (1978).

${ }^{46}$ J. T. Hougen, J. A. Mucha, D. A. Jennings, and K. M. Evenson, J. Mol. Spectrosc. 72, 463 (1978).

${ }^{47}$ K. Suzuki and K. Kuchitsu, Chem. Phys. Lett. 56, 50 (1978).

${ }^{48}$ K. P. Huber and G. Herzberg, Constants of Diatomic Molecules (Van Nostrand Reinhold, New York, 1979).

${ }^{49}$ K. H. Becker, H. H. Brenig, and T. Tatarczyk, Chem. Phys. Lett. 71, 242 (1980).

${ }^{50}$ M. Ortiz and J. Campos, Physica (Utrecht) 114, 135 (1982).

${ }^{51}$ M. Bogey, C. Demuynck, and J. L. Destombes, Chem. Phys. Lett. 100, 105 (1983)

${ }^{52}$ J. M. Brown and K. M. Evenson, Astrophys. J. 268, L51 (1983); J. Mol. Spectrosc. 98, 392 (1983).

${ }^{53}$ L. M. Ziurys, C. Henkel, and R. J. Saykally, Astrophys. J. 275, 175 (1983).

${ }^{54}$ C. R. Brazier and J. M. Brown, J. Chem. Phys. 78, 1608 (1983); Can. J. Phys. 62, 1563 (1984)

${ }^{55}$ K. G. Lubic and T. Amano, J. Chem. Phys. 81, 1655 (1984).

${ }^{56}$ P. Chen, W. A. Chupka, and S. D. Colson, Chem. Phys. Lett. 121, 405 (1985).

${ }^{57}$ T. C. Steimle, D. R. Woodward, and J. M. Brown, Astrophys. J. 294, L59 (1985).

${ }^{58}$ W. Ubachs, G. Meyer, J. J. Ter Meulen, and A. Dymanus, J. Chem. Phys. 84, 3032 (1986).

${ }^{59}$ J. B. Pallix, P. Chen, W. A. Chupka, and S. D. Colson, J. Chem. Phys. 84, 5208 (1986)

${ }^{60}$ N. Yishiyama, H. Sekiya, and Y. Nishimura, J. Chem. Phys. 84, 5213 (1986).

${ }^{61}$ W. Ubachs, W. M. van Herpen, J. J. ter Meulen, and A. Dymanus, J. Chem. Phys. 84, 6575 (1986).

${ }^{62}$ S. Zabarrnick, J. W. Fleming, and M. C. Lin, J. Chem. Phys. 85, 4373 (1986).

${ }^{63}$ J. J. Novoa and F. Mota, Chem. Phys. Lett. 123, 399 (1986).

${ }^{64}$ P. Chen, J. B. Pallix, W. A. Chupka, and S. D. Colson, J. Chem. Phys. 86, 516 (1987).

${ }^{65}$ P. F. Bernath, J. Chem. Phys. 86, 4838 (1987).

${ }^{66}$ J. W. Hudgens, D. J. Bogan, C. S. Dulcey, and G. R. Long, J. Chem. Phys. 87, 4546 (1987).
${ }^{67}$ E. Palazzi, N. Mandolesi, and P. Crane, Astrophys. J. 326, 905 (1988).

${ }^{68}$ C. Ye, M. Suto, and L. C. Lee, J. Chem. Phys. 89, 2797 (1988).

${ }^{69}$ S. R. Federman and W. T. Huntress, Jr., Astrophys. J. 338, 140 (1989).

${ }^{70}$ L. Magnani, E. A. Lada, G. Sandell, and L. Blitz, Astrophys. J. 339, 244 (1989).

${ }^{71}$ R. G. Macdonald and K. Liu, J. Chem. Phys. 91, 821 (1989).

${ }^{72}$ F. J. Lovas and R. D. Suenrram, J. Phys. Chem. Ref. Data 18, 1245 (1989).

${ }^{73}$ F. Melen, N. Grevesse, A. J. Sauval, C. B. Farmer, R. H. Norton, H. Bredohl, and I. Dubois, J. Mol. Spectrosc. 134, 305 (1989).

${ }^{74}$ T. C. Steimle, D. F. Nachman, D. A. Fletcher, and J. M. Brown, J. Mol. Spectrosc. 138, 222 (1989).

${ }^{75}$ S. M. Anderson and K. E. McCurdy, Chem. Phys. Lett. 157, 531 (1989).

${ }^{76}$ A. J. Dean and R. K. Hanson, J. Quant. Spectrosc. Radiat. Transf. 42, 375 (1989).

${ }^{77}$ T.-X. Xiang and W. A. Guillory, Chem. Phys. 130, 299 (1989).

${ }^{78}$ W. Bauer, B. Engelhardt, P. Wiesen, and K. H. Becker, Chem. Phys. Lett. 158, 321 (1989).

${ }^{79}$ Z. Bembenek, R. Kepa, A. Para, M. Rytel, M. Zachwieja, J. D. Janjic, and E. Marx, J. Mol. Spectrosc. 139, 1 (1990).

${ }^{80}$ J. Kouliadati, A. Czernichowski, J. J. Beulens, and D. C. Schram, J. Phys. (France) 51, 5297 (1990).

${ }^{81}$ V. McKoy, M. Braunstein, H. Rudolph, J. A. Stevens, S. N. Dixit, and D. L. Lynch, J. Electron Spectrosc. Relat. Phenom. 52, 597 (1990).

${ }^{82}$ D. L. Lambert, Y. Sheffer, and P. Crane, Astrophys. J. 359, L19 (1990).

${ }^{83}$ P. F. Bernath, C. R. Brazier, T. Olsen, R. Hailey, W. T. M. Fernando, C. Woods, and J. L. Hardwick, J. Mol. Spectrosc. 147, 16 (1991); 149, 563 (1991); 165, 310 (1994).

${ }^{84}$ J. Luque, J. Ruiz, and M. Martin, Chem. Phys. Lett. 202, 179 (1993).

${ }^{85}$ S. Couris, N. Anastasopoulou, and C. Fotakis, Chem. Phys. Lett. 223, 561 (1994).

${ }^{86}$ M. Zachwieja, J. Mol. Spectrosc. 170, 285 (1995).

${ }^{87}$ C. C. Wang, L. Nemes, and K. C. Lin, Chem. Phys. Lett. 245, 585 (1995).

${ }^{88}$ W. H. Basinger, W. G. Lawrence, and M. C. Heaven, J. Chem. Phys. 103, 7218 (1995).

${ }^{89}$ R. Kepa, A. Para, M. Rytel, and M. Zachwieja, J. Mol. Spectrosc. 178, 189 (1996).

${ }^{90}$ Y. K. Kim, M. A. Ali, and M. E. Rudd, J. Res. Natl. Inst. Stand. Technol. 102, 693 (1997)

${ }^{91}$ Z. Bembenek, R. Kepa, and M. Rytel, J. Mol. Spectrosc. 183, 1 (1997).

${ }^{92}$ L. A. Kuznetsova and N. F. Stepanof, Astron. Astrophys. Trans. 12, 289 (1997).

${ }^{93}$ T. Dunham, Jr., Publ. Astron. Soc. Pac. 49, 26 (1937).

${ }^{94}$ P. Swings and L. Rosefeld, Astrophys. J. 86, 483 (1937).

${ }^{95}$ T. Dunham, Jr., Publ. Am. Astron. Soc. 10, 123 (1940).

${ }^{96}$ A. McKellar and E. H. Richardson, Astrophys. J. 122, 196 (1955).

${ }^{97}$ L. Spitzer, Jr. and G. Field, Astrophys. J. 121, 300 (1955).

${ }^{98}$ C. E. Moore and H. P. Broida, J. Res. Natl. Bur. Stand., Sect. A 63, 19 (1959).

${ }^{99}$ C. Arpigny, Annu. Rev. Astron. Astrophys. 3, 351 (1965).

${ }^{100}$ P. Thaddeus and J. F. Clauser, Phys. Rev. Lett. 16, 819 (1966).

${ }^{101}$ O. E. H. Rydbeck, J. Ellder, and W. M. Irvine, Nature (London) 246, 466 (1973).

${ }^{102}$ B. E. Turner and B. Zuckerman, Astrophys. J. 187, L59 (1974).

${ }^{103}$ B. Zuckerman and B. E. Turner, Astrophys. J. 197, 123 (1975).

${ }^{104}$ D. McNally, Adv. Astron. Astrophys. 6, 173 (1978).

${ }^{105}$ D. L. Lambert, Mon. Not. R. Astron. Soc. 182, 249 (1978).

${ }^{106}$ Comets, edited by L. Wilkening (Univ. of Arizona, Tucson, 1982).

${ }^{107}$ A. C. Danks, S. R. Federman, and D. L. Lambert, Astron. Astrophys. 130, 62 (1984).

${ }^{108}$ Y. Chmielewski, Astron. Astrophys. 133, 83 (1984).

${ }^{109}$ S. T. Ridgway, D. F. Carbon, D. N. B. Hall, and J. Jewell, Astrophys. J., Suppl. 54, 177 (1984).

${ }^{110}$ D. J. Lien, Astrophys. J. 284, 578 (1984).

${ }^{111}$ A. J. Sauval and N. Grevesse, Astron. Express 1, 153 (1985).

${ }^{112}$ M. Jura and D. M. Meyer, Astrophys. J. 294, 238 (1985).

${ }^{113}$ D. L. Lambert, B. Gustafsson, K. Eriksson, and K. H. Hinkle, Astrophys. J., Suppl. 62, 373 (1986).

${ }^{114}$ G. J. Stacey, J. B. Lugten, and R. Genzel, Astrophys. J. 313, 859 (1987).

${ }^{115}$ M. Centurion and G. Vladilo, Astron. Astrophys. 251, 245 (1991).

${ }^{116}$ W. B. Somerville and I. A. Crawford, J. Chem. Soc., Faraday Trans. 89, 2261 (1993).

${ }^{117}$ W. Womack, B. L. Lutz, and R. M. Wagner, Astrophys. J. 433, 886 (1994). 
${ }^{118}$ R. Bleekrode and W. C. Nieuwpoort, J. Chem. Phys. 43, 3680 (1965).

${ }^{119}$ R. H. Barnes, C. E. Moeller, J. G. Kircher, and C. M. Verber, Appl. Opt. 12, 2531 (1973).

${ }^{120}$ A. G. Gaydon, in CRC Handbook of Spectroscopy, edited by J. W. Robinson (Chemical Rubber, Cleveland, 1974), Vol. 1, p. 755.

${ }^{121}$ S. V. Filseth, H. Zacharias, J. Danon, R. Wallenstein, and K. H. Welge, Chem. Phys. Lett. 58, 140 (1978).

${ }^{122}$ P. A. Bonczyk and J. A. Shirley, Combust. Flame 34, 253 (1979).

${ }^{123}$ J. E. Butler, J. W. Flemming, L. P. Goss, and M. C. Lin, Chem. Phys. 56, 355 (1981).

${ }^{124}$ K. Kohse-Höinghaus, W. Perc, and Th. Just, Ber. Bunsenges. Phys. Chem. 87, 1052 (1983).

${ }^{125}$ Y. Takubo, H. Yano, H. Matsuoka, and M. Shimazu, J. Quant. Spectrosc. Radiat. Transf. 30, 163 (1983).

${ }^{126}$ J. J. Horvath, K. M. Pamidimukkala, W. B. Person, and A. E. S. Green, J. Quant. Spectrosc. Radiat. Transf. 31, 189 (1984).

${ }^{127}$ R. J. Cattolica, D. Stepowski, D. Puechberty, and M. Cottereau, J. Quant. Spectrosc. Radiat. Transf. 32, 363 (1984).

${ }^{128}$ J. A. Barnard and J. N. Bradley, Flame and Combustion (Chapman and Hall, New York, 1985).

${ }^{129}$ N. L. Garlant and D. R. Crosley, Appl. Opt. 24, 4229 (1985); J. Quant. Spectrosc. Radiat. Transf. 33, 591 (1985).

${ }^{130}$ M. S. Chou and A. M. Dean, Int. J. Chem. Kinet. 17, 1103 (1985).

${ }^{131}$ R. G. Joklik and J. W. Daily, Combust. Flame 69, 211 (1987).

${ }^{132}$ J. B. Jeffries, R. A. Copeland, and D. R. Crosley, J. Quant. Spectrosc. Radiat. Transf. 37, 419 (1987).

${ }^{133}$ L. Lynds and B. A. Woody, Appl. Opt. 27, 1225 (1988).

${ }^{134}$ K. J. Rensenberger, M. J. Dyer, and R. A. Copeland, Appl. Opt. 27, 3679 (1988).

${ }^{135}$ K. D. Bayes, Chem. Phys. Lett. 152, 424 (1988).

${ }^{136}$ P. J. H. Tjossem and K. C. Smyth, Chem. Phys. Lett. 144, 51 (1988)

${ }^{137}$ D. E. Phippen and K. D. Bayes, Chem. Phys. Lett. 164, 625 (1989).

${ }^{138}$ Z. Hou and K. D. Bayes, J. Phys. Chem. 96, 5685 (1992).

${ }^{139}$ S. Williams, D. S. Green, S. Sethuramen, and R. N. Zare, J. Am. Chem. Soc. 114, 9122 (1992).

${ }^{140}$ M. C. Wu and D. W. Goodman, J. Am. Chem. Soc. 116, 1364 (1994).

${ }^{141}$ T. Takaoka, T. Sekitani, T. Arruga, and M. Nishijima, Surf. Sci. 306, 179 (1994).

${ }^{142}$ D. Feldmann, Z. Naturforsch. 25a, 621 (1970).

${ }^{143}$ A. Kasdan, E. Herbst, and W. C. Lineberger, Chem. Phys. Lett. 31, 78 (1975).

${ }^{144}$ T. Nelis, J. M. Brown, and K. M. Evenson, J. Chem. Phys. 88, 2087 (1988); 92, 4067 (1990).

${ }^{145}$ J. M. Brown and K. M. Evenson, J. Mol. Spectrosc. 136, 68 (1989).

${ }^{146}$ M. Danielsson, P. Erman, A. Hishikawa, M. Larson, E. Rachlew-Källne, and G. Sundström, J. Phys. Chem. 98, 9405 (1993).

${ }^{147}$ I. Morino, K. Matsumura, and K. Kawaguchi, J. Mol. Spectrosc. 174, 123 (1995).

${ }^{148}$ J. Richter and K. F. Tonner, Z. Astrophys. 67, 155 (1967).

${ }^{149}$ T. C. Steimle, D. R. Woodward, and J. M. Brown, J. Chem. Phys. 85, 1276 (1986).

${ }^{150}$ A. Para, J. Phys. B 29, 5765 (1996).

${ }^{151}$ M. Zachwieja, J. Mol. Spectrosc. 182, 18 (1997).

${ }^{152}$ R. Bhatnagar et al., J. Mol. Spectrosc. 85, 348 (1981).

${ }^{153}$ V. S. Langford and B. E. Williamson, J. Phys. Chem. 102, 138 (1998).

${ }^{154}$ R. S. Mulliken, Rev. Mod. Phys. 4, 1 (1932).

${ }^{155}$ H. A. Kramers and D. ter Haar, Bull. Astron. Inst. Netherlands 10, 371 (1946).

${ }^{156}$ D. R. Bates and L. Spitzer, Astrophys. J. 113, 441 (1951).

${ }^{157}$ K. Niira and K. Oohata, J. Phys. Soc. Jpn. 7, 61 (1952).

${ }^{158}$ J. Higuchi, Bull. Chem. Soc. Jpn. 26, 1 (1953).

${ }^{159}$ J. Higuchi, J. Chem. Phys. 22, 1339 (1954).

${ }^{160}$ M. Krauss, J. Chem. Phys. 28, 1021 (1958).

${ }^{161}$ M. Krauss and J. F. Wehner, J. Chem. Phys. 29, 1287 (1958).

${ }^{162}$ A. C. Hurley, Proc. R. Soc. London, Ser. A 248, 119 (1958); 249, 402 (1959).

${ }^{163}$ J. M. Foster and S. F. Boys, Rev. Mod. Phys. 32, 305 (1960).

${ }^{164}$ D. M. Bishop, J. R. Hoyland, and R. G. Parr, Mol. Phys. 6, 467 (1963).

${ }^{165}$ P. E. Cade and W. M. Huo, J. Chem. Phys. 45, 1063 (1966).

${ }^{166}$ P. E. Cade and W. M. Huo, J. Chem. Phys. 47, 614 (1967).

${ }^{167}$ P. E. Cade, Proc. Phys. Soc. London 91, 842 (1967).

${ }^{168}$ W. M. Huo, J. Chem. Phys. 49, 1482 (1968).

${ }^{169}$ C. F. Bender and E. R. Davidson, Phys. Rev. 183, 23 (1969).

${ }^{170}$ H. P. D. Liu and G. Verhaegen, J. Chem. Phys. 53, 735 (1970).
${ }^{171}$ R. K. Hinkley, J. A. Hall, T. E. H. Walker, and W. G. Richards, J. Phys. B 5, 204 (1972).

${ }^{172}$ R. A. Bain and J. N. Bardsley, J. Phys. B 5, 277 (1972).

${ }^{173}$ T. E. H. Walker and H. P. Kelly, J. Chem. Phys. 57, 936 (1972); Phys. Rev. A 5, 1986 (1972).

${ }^{174}$ P. M. Solomon and W. Klemperer, Astrophys. J. 178, 389 (1972).

${ }^{175}$ G. C. Lie, J. Hinze, and B. Liu, J. Chem. Phys. 57, 625 (1972); 59, 1872 (1973); 59, 1887 (1973).

${ }^{176}$ I. Botterud, A. Lofthus, and L. Veseth, Phys. Scr. 8, 218 (1973).

${ }^{177}$ P. S. Julienne and M. Krauss, Molecules in the Galactic Environment (Wiley, New York, 1973), p. 353.

${ }^{178}$ W. H. Smith, H. S. Liszt, and B. L. Lutz, Astrophys. J. 183, 69 (1973).

${ }^{179}$ J. N. Bardsley and B. R. Junker, Astrophys. J. 183, L135 (1973).

${ }^{180}$ M. Krauss and P. S. Julienne, Astrophys. J. 183, L139 (1973).

${ }^{181}$ W. J. Stevens, J. Chem. Phys. 58, 1264 (1973).

${ }^{182}$ G. Das, A. C. Wahl, and W. J. Stevens, J. Chem. Phys. 61, 433 (1974).

${ }^{183}$ B. M. Krupp, Astrophys. J. 189, 389 (1974).

${ }^{184}$ R. E. Hammersley and W. G. Richards, Nature (London) 251, 597 (1974).

${ }^{185}$ P. W. Abegg and T.-K. Ha, Mol. Phys. 27, 763 (1974).

${ }^{186}$ W. Meyer and P. Rosmus, J. Chem. Phys. 63, 2356 (1975).

${ }^{187}$ J. F. Bazet, C. Harel, R. McCarroll, and A. Riera, Astron. Astrophys. 43, 223 (1975)

${ }^{188}$ J. Hinze, G. C. Lie, and B. Liu, Astrophys. J. 196, 621 (1975).

${ }^{189}$ D. H. Levy and J. Hinze, Astrophys. J. 200, 236 (1975); 211, 980 (1977).

${ }^{190}$ J. H. Black and A. Dalgarno, Astrophys. J., Suppl. 34, 405 (1977).

${ }^{191}$ J. Barsuhn, Astron. Astrophys., Suppl. Ser. 28, 453 (1977).

${ }^{192}$ R. E. Hammersley and W. G. Richards, Astrophys. J. 214, 951 (1977).

${ }^{193}$ A. Giusti-Suzor and H. Lefebvre-Brion, Astrophys. J. 214, L101 (1977).

${ }^{194}$ J. Barsuhn and R. K. Nesbet, J. Chem. Phys. 68, 2783 (1978).

${ }^{195}$ N. Elander, M. Hehenberger, and P. R. Bunker, Phys. Scr. 20, 631 (1979).

${ }^{196}$ H. Sun and K. F. Freed, Chem. Phys. Lett. 78, 531 (1981).

${ }^{197}$ Z. C. Kornblum, J. Chem. Phys. 75, 5816 (1981).

${ }^{198}$ M. Larsson and P. E. M. Siegbahn, J. Chem. Phys. 79, 2270 (1983).

${ }^{199}$ J. S. Wright and R. J. Williams, J. Chem. Phys. 79, 2893 (1983).

${ }^{200}$ J. A. Pople, M. J. Frisch, B. T. Luke, and J. S. Binkley, Int. J. Quantum Chem., Quantum Chem. Symp. 17, 2513 (1983).

${ }^{201}$ H. Sun and K. F. Freed, J. Chem. Phys. 80, 779 (1984).

${ }^{202}$ B. F. Minaev, Opt. Spectrosc. 58, 328 (1985).

${ }^{203}$ P. Kristianen and L. Veseth, J. Chem. Phys. 84, 6336 (1986).

${ }^{204}$ C. W. Bauschlicher, Jr. and S. R. Langhoff, Chem. Phys. Lett. 135, 67 (1987).

${ }^{205}$ E. F. Van Dishoeck, J. Chem. Phys. 86, 196 (1987).

${ }^{206}$ K. K. Baeck and Y. S. Lee, Chem. Phys. Lett. 147, 367 (1988).

${ }^{207}$ S. Biskupic and R. Klein, J. Mol. Struct. 170, 27 (1988).

${ }^{208}$ E. A. Carter and W. A. Goddard III, J. Chem. Phys. 88, 3132 (1988).

${ }^{209}$ H. Sun and K. F. Freed, J. Chem. Phys. 88, 2659 (1988); 89, 5355 (1988).

${ }^{210}$ B. Engels, S. D. Peyerimhoff, S. P. Karrna, and F. Grein, Chem. Phys. Lett. 152, 397 (1988).

${ }^{211}$ B. Engels and S. D. Peyerimhoff, Z. Phys. D 13, 335 (1989).

${ }^{212}$ J. M. L. Martin, J. P. Francois, and R. Gijbels, J. Comput. Chem. 10, 152 (1989); Chem. Phys. Lett. 157, 217 (1989); 163, 387 (1989).

${ }^{213}$ G. Theodorakopoulos, I. D. Petsalakis, R. J. Buenker, and M. Honigmann, Chem. Phys. 137, 137 (1989).

${ }^{214}$ N. Damotta, D. Joaquim, and M. A. C. Nascimento, Quim. Nova 12, 384 (1989).

${ }^{215}$ H. Rudolph, J. A. Stevens, V. McKov, and M. T. Lee, J. Chem. Phys. 91, 1374 (1989).

${ }^{216}$ K. Ohwada, Spectrochim. Acta A 45, 487 (1989); 46, 1461 (1990).

${ }^{217}$ I. Carmichael, J. Phys. Chem. 94, 5734 (1990).

${ }^{218}$ T. Momose, M. Yamaguchi, and T. Shida, J. Chem. Phys. 93, 7284 (1990).

${ }^{219}$ A. Para, J. Phys. B 24, 3179 (1991).

${ }^{220}$ A. W. Kanzler, H. Sun, and K. F. Freed, Int. J. Quantum Chem. 39, 269 (1991).

${ }^{221}$ A. W. Kanzler, K. F. Freed, and H. Sun, J. Chem. Phys. 96, 5245 (1992).

${ }^{222}$ D. Jayatilaka and T. J. Lee, Chem. Phys. Lett. 199, 211 (1992).

${ }^{223}$ R. S. Grev and H. F. Schaefer III, J. Chem. Phys. 97, 8389 (1992).

${ }^{224}$ K. A. Peterson, R. A. Kendall, and T. H. Dunning, Jr., J. Chem. Phys. 99, 1930 (1993).

${ }^{225}$ T. J. Lee and D. Jayatilaka, Chem. Phys. Lett. 201, 1 (1993).

${ }^{226}$ J. Wang and V. H. Smith, Jr., Int. J. Quantum Chem. 49, 147 (1994). 
${ }^{227}$ B. Engels, J. Chem. Phys. 100, 1380 (1994).

${ }^{228}$ H. Hettema and D. R. Yarkony, J. Chem. Phys. 100, 8991 (1994).

${ }^{229}$ N. Ishii and T. Shimizu, Chem. Phys. Lett. 235, 614 (1995).

${ }^{230}$ J. Luque and D. R. Crosley, J. Chem. Phys. 104, 2146 (1996).

${ }^{231}$ X. Li and J. Paldus, J. Chem. Phys. 104, 9555 (1996).

${ }^{232}$ A. Borrmann and R. O. Jones, Chem. Phys. Lett. 252, 1 (1996)

${ }^{233}$ K. A. Peterson and T. H. Dunning, J. Chem. Phys. 106, 4119 (1997).

${ }^{234}$ J. M. L. Martin, Chem. Phys. Lett. 273, 98 (1997); 292, 411 (1998).

${ }^{235}$ T. H. Dunning, Jr., J. Chem. Phys. 90, 1007 (1989); A. K. Wilson, T. V. Maurjk, and T. H. Dunning, Jr., J. Mol. Struct.: THEOCHEM 388, 339 (1997)
${ }^{236}$ MOLPRO is a package of ab initio programs written by H.-J. Werner and P. J. Knowles, with contributions from J. Almlöf, R. D. Amos, A. Berning, M. J. O. Deegan, F. Eckert, S. T. Elbert, C. Hambel, R. Lindh, W. Meyer, A. Nicklass, K. Peterson, R. Pitzer, A. J. Stone, P. R. Taylor, M. E. Mura, P. Pulay, M. Schuetz, H. Stoll, T. Thorsteinsson, and D. L. Cooper.

${ }^{237}$ J. L. Dunham, Phys. Rev. 41, 721 (1932).

${ }^{238}$ H. Partridge, J. Chem. Phys. 90, 1043 (1989).

${ }^{239}$ C. E. Moore, Atomic Energy Levels, NSRDS-NBS Circular 3 (U.S. GPO, Washington, DC, 1971).

${ }^{240}$ A. Kumar, C.-C. Hsiao, W.-C. Hung, and Y.-P. Lee, J. Chem. Phys. 109, 3824 (1998). 